\title{
1 Non-canonical aberrant DNA hypermethylation in glioma
}

2

3 Agustin F. Fernandez ${ }^{1, \dagger},{ }^{*}$, Gustavo F. Bayón ${ }^{1, \dagger}$, Marta I. Sierra ${ }^{1}$, Rocio G. Urdinguio ${ }^{2}$, 4 Estela G. Toraño ${ }^{1,2}$, Maria García ${ }^{1,2}$, Antonella Carella ${ }^{1,2}$, Virginia Lopez ${ }^{2}$, Pablo 5 Santamarina $^{1,2}$, Thalia Belmonte ${ }^{1,2}$, Juan Ramon Tejedor ${ }^{1}$, Isabel Cobo ${ }^{1,3}$, Pablo 6 Menendez $^{3,4}$, Cristina Mangas ${ }^{1}$, Cecilia Ferrero ${ }^{1}$, Luís Rodrigo ${ }^{5}$, Aurora Astudillo ${ }^{6}$, 7 Ignacio Ortea $^{7}$, Sergio Cueto Díaz ${ }^{8}$, Pablo Rodríguez-Gonzalez ${ }^{9}$, J. Ignacio García 8 Alonso $^{9}$, Manuela Mollejo $^{10}$, Bárbara Meléndez ${ }^{10}$, Gemma Dominguez ${ }^{11}$, Felix 9 Bonilla $^{11}$, and Mario F. Fraga ${ }^{2, *}$

${ }^{1}$ Institute of Oncology of Asturias (IUOPA), ISPA-HUCA, Universidad de Oviedo, Oviedo, Spain.

${ }^{2}$ Nanomaterials and Nanotechnology Research Center (CINN-CSIC)-Universidad de OviedoPrincipado de Asturias, Spain.

${ }^{3}$ Josep Carreras Leukemia Research Institute and Department of Biomedicine, School of Medicine, University of Barcelona, Barcelona, Spain

${ }^{4}$ Institució Catalana de Recerca i Estudis Avançats (ICREA) and Centro de Investigacion Biomedica en Red en Cancer CIBER-ONC, ISCIII, Barcelona, Spain.

${ }^{5}$ Department of Gastroenterology, Hospital Universitario Central de Asturias (HUCA), Oviedo, Spain.

${ }^{6}$ Department of Pathology, Hospital Universitario Central de Asturias and Instituto Universitario de Oncología del Principado de Asturias, Oviedo, Spain.

${ }^{7}$ Proteomics Unit, IMIBIC, Maimonides Institute for Biomedical Research, Córdoba, Spain.

${ }^{8}$ Mass Spectrometry Unit, University of Oviedo.

${ }^{9}$ Department of Physical and Analytical Chemistry, University of Oviedo

${ }^{10}$ Department of Pathology, Hospital Virgen de la Salud, Toledo, Spain. Avd. Barber 30, Toledo 45005

${ }^{11}$ Servicio de Oncología Médica, Hospital Universitario Puerta de Hierro. Majadahonda, Facultad de Medicina, Universidad Autónoma de Madrid, Madrid, Spain

*Corresponding Authors:

Mario F. Fraga: mffraga@cinn.es

Agustin F Fernandez: affernandez@hca.es

†Same contribution. 


\section{Abstract}

37 Aberrant DNA hypermethylation is a hallmark of cancer although the underlying 38 molecular mechanisms are still poorly understood. To study the possible role of 539 hydroxymethylcytosine $(5 \mathrm{hmC})$ in this process we analyzed the global and locus40 specific genome-wide levels of $5 \mathrm{hmC}$ in primary samples from 54 gliomas and 72 41 colorectal cancer patients. Levels of $5 \mathrm{hmC}$ in colorectal cancer were very low and no 42 consistent changes were detected between control tissues and tumors. As expected, 43 levels of $5 \mathrm{hmC}$ in non-tumoral brain samples were high and significantly reduced at the 44 49,601 CpG sites in gliomas. Strikingly, hypo-hydroxymethylation at 4,627 (9.3\%) of 45 these $\mathrm{CpG}$ sites was associated with aberrant DNA hypermethylation. The DNA regions 46 containing these $\mathrm{CpG}$ sites were enriched in $\mathrm{H} 3 \mathrm{~K} 4 \mathrm{me} 2$, and presented a different 47 genuine chromatin signature to that characteristic of the genes classically aberrantly 48 hypermethylated in cancer. We conclude that this data identifies a novel $5 \mathrm{hmC}$ 49 dependent non-canonical class of aberrant DNA hypermethylation in glioma. 


\section{Introduction}

53 DNA methylation at the fifth position of cytosine $(5 \mathrm{mC})$ has been one of the most 54 studied epigenetic modifications in mammals to date. $5 \mathrm{mC}$ is involved in the regulation of multiple physiological and pathological processes, including cancer, and when located at gene promoters, it is usually linked to transcriptional repression.

57 As distinctive features of tumorigenesis, local DNA hypermethylation and global 58 hypomethylation have been attributed to changes in $5 \mathrm{mC}$ levels $[10 ; 11]$. However, the 59 discovery a few years ago, of 5-hydroxymethylcytosine (5hmC), a new epigenetic mark 60 resulting from $5 \mathrm{mC}$ oxidation, is reshaping our view of the cancer epigenome [29; 47].

61 This $5 \mathrm{mC}$ to $5 \mathrm{hmC}$ conversion in mammals is mediated by ten-eleven translocation proteins (TET1, TET2, and TET3), a family of $\alpha$-ketoglutarate ( $\alpha \mathrm{KG})$ and Fe(II)dependent dioxygenases[21;47]. Global levels of $5 \mathrm{hmC}$ in the genome fluctuate considerably according to tissue type, and are consistently around 10-fold lower than those of $5 \mathrm{mC}$, though it is interesting that the highest levels of both marks are found in brain $[13 ; 16 ; 24 ; 32 ; 37 ; 44]$.

67 Several studies suggest that $5 \mathrm{hmC}$ is not only an intermediate of DNA demethylation, but that it also plays a role in cancer biology $[23 ; 33 ; 41 ; 46 ; 55]$. In this vein, a broad loss of $5 \mathrm{hmC}$ has been reported in different human cancers including melanoma, glioma, breast, colon, gastric, kidney, liver, lung, pancreatic, and prostate cancers [17; $23 ; 27 ; 30 ; 32 ; 34 ; 55]$.

72 The fact that there are now methods available that distinguish $5 \mathrm{mC}$ and $5 \mathrm{hmC}$ positions 73 at single-base resolution within the genome prompted us to reassess the role of DNA 74 methylation status in tumorigenesis from a $5 \mathrm{hmC}$ perspective. The method used here allowed us to describe global and genome-wide locus-specific $5 \mathrm{mC}$ and $5 \mathrm{hmC}$ patterns in colon and brain samples, to identify a specific chromatin signature associated with changes of these epigenetic marks in cancer and, most notably, to describe a novel noncanonical type of aberrant DNA hypermethylation in cancer. 


\section{Results}

\section{Global changes of $5 \mathrm{mC}$ and $5 \mathrm{hmC}$ in cancer}

To evaluate the role of $5 \mathrm{hmC}$ in the changes of DNA methylation observed in cancer, we first analyzed the levels of $5 \mathrm{hmC}$ and $5 \mathrm{mC}$ at repetitive DNA in 84 normal and 123 tumor samples obtained from patients with colorectal cancer and glioma. Bisulfite pyrosequencing was used to determine the level of both epigenetic modifications in 4 different types of repeated DNA: the retrotransposons LINE-1 and AluYb8, and the pericentromeric tandem repeats Sat-alpha and NBL-2 [49]. These 4 DNA regions contain most of the genomic methylation and, consequently, global DNA methylation level is highly dependent on their $5 \mathrm{mC}$ content [51]. As expected, $5 \mathrm{mC}$ levels at most repeated DNA in healthy tissue was high, and was reduced in tumor samples (Figure 1A). In contrast, the levels of $5 \mathrm{hmC}$ at repeated DNA in healthy tissue was very low, and tumoral tissue showed even lower levels of $5 \mathrm{hmC}$ in these DNA regions (Figure 1B). However, the differences were very small and, consequently, they cannot explain the global loss of this mark in cancer observed by mass spectrometry $[23 ; 27 ; 28 ; 39]$.

\section{$5 \mathrm{mC}$ and $5 \mathrm{hmC}$ profiling in colorectal and brain tissue}

As changes in $5 \mathrm{hmC}$ at repeated DNA were not able to explain the global changes previously observed by mass spectrometry, we hypothesized that these changes primarily occur at single copy sequences. To investigate this possibility in more detail, we first used $450 \mathrm{~K}$ Infinium methylation arrays to determine the level and genomic distribution of $5 \mathrm{mC}$ and $5 \mathrm{hmC}$ at $479,423 \mathrm{CpG}$ sites in 11 non-tumoral colorectal samples and 5 healthy brain tissue samples, all from different donors. A preliminary examination of the data revealed that the beta values of the oxidized samples (true $5 \mathrm{mC}$ ) were much lower than their non-oxidized counterparts $(5 \mathrm{mC}+5 \mathrm{hmC})$ in brain (Wilcoxon rank sum test; $\mathrm{p}<0.001 ; \mathrm{W}=2.34 \mathrm{e} 13$ ) than in colorectal (Wilcoxon rank sum test; $\mathrm{p}<0.001 ; \mathrm{W}=5.52 \mathrm{e} 13$ ) tissues (see Materials and Methods), which indicates that, as expected, levels of $5 \mathrm{hmC}$ are higher in brain tissue than in the colon (Figure 2A). In line with this, we identified 111,633 and 5,089 hydroxymethylated $\mathrm{CpG}$ sites $(5 \mathrm{hmC}$ sites) in brain and colorectal tissue respectively (Figure 2A, and Supplementary Table 1 and 2) (see Materials and Methods).

The analysis of the genomic distribution of the $5 \mathrm{hmC}$ sites showed that, in both colorectal and brain tissue, hydroxymethylation is enriched at the low CpG-density regions interrogated by the array (Wilcoxon non-parametric test; $p<0.001, D=-0.29$, and 
$113 \mathrm{p}<0.001, \mathrm{D}=-0.5$, respectively) (Figure 2B). Consequently, the $5 \mathrm{hmC}$ sites were

114 enriched in non-CpG islands (non-CGI) in both colon and brain (chi-square test;

$115 \mathrm{p}<0.001 ; \mathrm{OR}=1.93$, and $\mathrm{p}<0.001, \mathrm{OR}=3.45$, respectively) and infrequent in CGIs (chi-

116 square test; $\mathrm{p}<0.001, \mathrm{OR}=0.14$, and $\mathrm{p}<0.001, \mathrm{OR}=0.13$ ) (Figure 2C). With respect to

117 genes, $5 \mathrm{hmC}$ sites were enriched in introns in both brain and colorectal tissue (chi-

118 square test; $\mathrm{p}<0.001, \mathrm{OR}=1.82$, and $\mathrm{p}<0.001, \mathrm{OR}=1.76$, respectively), but were less

119 frequent than expected in intergenic regions in colorectal tissue and in gene promoters

120 in brain tissue (chi-square test; $\mathrm{p}<0.001, \mathrm{OR}=0.58$, and $\mathrm{p}<0.001, \mathrm{OR}=0.6$ ) (Figure 2D).

121 Moreover, hydroxymethylated $\mathrm{CpG}$ sites were farther away from centromeres in brain

122 (Wilcoxon non-parametric test, $\mathrm{p}<0.001, \mathrm{D}=0.01$ ) and telomeres in both colorectal

123 tissues and brain (Wilcoxon non-parametric test, $\mathrm{p}<0.001, \mathrm{D}=0.07$, and $\mathrm{p}<0.001$,

$124 \mathrm{D}=0.02$, respectively) than the median in terms of other background sites, although the

125 size of these shifts was rather small (Figure 2-figure supplement 1A).

126 To identify possible chromatin marks associated with $5 \mathrm{hmC}$ sites in colorectal and brain

127 tissue, we compared these $\mathrm{CpG}$ sites with previously published data on a range of

128 histone modifications and chromatin modifiers in 10 different cell types (see Materials

129 and Methods) (Figure 2E). This approach identified statistically significant associations

130 (Fisher's exact test; $\mathrm{p}<0.05$ ) between the $5 \mathrm{hmC}$ sites and the active histone marks

$131 \mathrm{H} 3 \mathrm{~K} 4 \mathrm{me} 1, \mathrm{H} 3 \mathrm{~K} 36 \mathrm{me} 3$, and H4K20me1, in both colorectal and brain tissue (Figure

132 2E). Interestingly, in colorectal tissue, $5 \mathrm{hmC}$ was also enriched in other activating

133 histone posttranslational modifications (PTMs) such as H3K79me2, and H3K4me2

134 (Figure2E). Finally, a similar framework was used to test for the enrichment of our

135 selected probes over the computer-generated chromatin segmentation states from the

136 ENCODE ChromHMM project (see Materials and Methods). In total, fifteen states were

137 used to segment the genome, and these were then grouped and colored to highlight

138 predicted functional elements. This approach showed that the hmC sites were

139 significantly enriched in states associated with enhancers and transcription in both

140 colorectal and brain tissue (Fisher's exact test; $\mathrm{p}<0.05)$ (Figure 2-figure supplement

141 1B).

143 Locus-specific alterations of $5 \mathbf{h m C}$ in colorectal cancer (CRC) and glioma

144 To identify differentially hydroxymethylated $\mathrm{CpG}$ sites (d5hmC) at single copy 145 sequences in cancer, we used $450 \mathrm{~K}$ methylation arrays to analyze 11 additional 146 colorectal tumors and 9 primary tumors obtained from patients with glioma (see 
147 Materials and Methods). A total of 49,601 CpG sites that were hypohydroxymethylated 148 were identified in gliomas, but almost no hyper-hydroxymethylated sites were found 149 (see Materials and Methods) (Figure 3A and Supplementary Table 3). In contrast, no 150 significant methylation changes were found in colorectal tumors (Figure 3A) and thus 151 subsequent stages of the study focused on glioma alone. Hierarchical clustering using 152 the differentially hydroxymethylated $\mathrm{CpG}$ sites showed the correct classification of 153 normal and tumor samples (Figure 3B). The analysis of the genomic distribution of the 154 hypo-hydroxymethylated $\mathrm{CpG}$ sites in gliomas showed an enrichment at low $\mathrm{CpG}$ 155 density regions (Wilcoxon rank sum test, $\mathrm{p}<0.001, \mathrm{D}=-0.41$ ), and consequently at non$156 \mathrm{CpG}$ islands (chi-squared test, $\mathrm{p}<0.001$, $\mathrm{OR}=2.53$ ) (Figure 3C). With respect to gene 157 location, hypo-hydroxymethylation was more frequent in introns (chi-squared test, $158 \mathrm{p}<0.001, \mathrm{OR}=1.77$ ) (Figure 3C).

159 To identify possible chromatin signatures associated with DNA hypo160 hydroxymethylation in gliomas, we compared our list of hypo-hydroxymethylated $\mathrm{CpG}$ 161 sites with previously published data on a range of histone modifications and chromatin modifiers in 11 different cell types (see Materials and Methods) (Figure 3D). Interestingly, this approach showed an enrichment of hypo-hydroxymethylation at chromatin regions marked with the activating histone PTMs H3K4me1, H3K36me3, H4K20me1 and H3K79me2 (Fisher's exact test, p<0.05) (Figure 3D), but not with the repressive histone modification $\mathrm{H} 3 \mathrm{~K} 27 \mathrm{me}$, which has been previously shown to be associated with aberrant DNA hypermethylation in cancer [38; 52] (Figure 3D). A similar framework was used to test for the enrichment of our selected probes over the computer-generated chromatin segmentation states from the ENCODE ChromHMM project. Using this approach, we found that hypohydroxymethylated $\mathrm{CpG}$ sites were significantly associated with transcription regulation and enhancers (Fisher's exact test; $\mathrm{p}<0.05)$ (Figure 3E).

DNA hypo-hydroxymethylation identifies a novel type of non-canonical aberrant DNA hyper-methylation in glioma

176 To study the relationship between changes in $5 \mathrm{mC}$ and $5 \mathrm{hmC}$ in glioma, we first 177 identified aberrantly methylated $\mathrm{CpG}(\mathrm{d} 5 \mathrm{mC})$ sites. The comparison of the methylation 178 data between tumoral and control samples (see Materials and Methods) identified 2,727 179 hypo- and 12,050 hyper-methylated CpG sites in gliomas (Supplementary Tables 4 180 and 5). Next, we compared these $\mathrm{d} 5 \mathrm{mC}$ sites with the previously identified hypo- 
181 hydroxymethylated CpG sites (Figure 3A, Supplementary Table 3). Interestingly, this 182 approach showed that $4,627(38.4 \%)$ of the CpG sites aberrantly hypermethylated in 183 gliomas also lose 5hmC (Figure 4A, Supplementary Table 6).

184 To investigate, at a functional genomic level, the characteristics of these two classes of 185 aberrantly hypermethylated $\mathrm{CpG}$ sites in gliomas we first analyzed their genomic 186 distribution in relation to density of $\mathrm{CpG}$ sites and we found that the hypermethylated $187 \mathrm{CpG}$ sites that lose $5 \mathrm{hmC}$ (hyper5mC-hypo5hmC) were enriched in low density $\mathrm{CpG}$ 188 regions (Wilcoxon rank sum test, $\mathrm{p}<0.001, \mathrm{D}=-0.11$ ) as compared with the 189 hypermethylated $\mathrm{CpG}$ sites that showed no changes in $5 \mathrm{hmC}$ (hyper5mC) (Wilcoxon 190 rank sum test, $\mathrm{p}<0.001, \mathrm{D}=-0.23$ ) (Figure 4B, Supplementary Tables 6 and 7). In line 191 with this, hyper5mC-hypo5hmC sites were strongly depleted from CGIs (chi-squared 192 test, $\mathrm{p}<0.001, \mathrm{OR}=0.42$ ) (Figure 4B). Hierarchical clustering using the differentially 193 methylated CpG sites showed that the hyper5mC-hypo5hmC sites were slightly more 194 methylated in control brain samples than the hyper $5 \mathrm{mC}$ sites, and that they were more 195 uniformly hypermethylated in glioma (Figure 4C). To further corroborate our results, 196 we took advantage of recently published data on the whole-genome bisulfite sequencing 197 (WGBS) in glioma [42]. We found that, in addition to a large percentage of CpGs (n: 1984,$051 ; 88 \%$ ) showing the same patterns of change as in our methylation arrays, the 199 WGBS analysis identified more than $10^{6}$ new hyper5mC-hypo5hmC sites, thus 200 confirming that this is a frequent event in glioma (Figure 4-figure supplement 1).

201 Next, to identify possible chromatin signatures associated with the two classes of 202 aberrantly hypermethylated $\mathrm{CpG}$ sites in gliomas, we compared our data with previously published data on a range of histone modifications and chromatin modifiers in 11 different cell types (see Materials and Methods) (Figure 5A). This approach confirmed the association between hyper $5 \mathrm{mC}$ and the repressive histone marks H3K9me3 and H3K27me3 (Fisher's exact test, p<0.05) [36; 38; 52]. The hyper5mChypo5hmC sites showed a completely different chromatin signature, with enrichment in 208 the activating histone PTMs H3K4me1, H3K36me3, H3K79me2 and H4K20me1 209 (Fisher's exact test, $\mathrm{p}<0.05$ ) (Figure 5A). Notably, as compared with the chromatin 210 signature of the whole set of hypo-hydroxymethylated CpGs in glioma, these CpG sites 211 were particularly enriched at the H3K4me2 histone mark (Fisher's exact test, $\mathrm{p}<0.001$, 212 OR in $[1.19,1.78]$ for all cell lines in the Broad Histone project) (Figure 5B).

213 These results indicate that the hyper $5 \mathrm{mC}$ sites behave like the aberrantly 214 hypermethylated canonical $\mathrm{CpG}$ sites in cancer, whilst the hyper5mC-hypo5hmC sites 
215 represent a novel and functionally different non-canonical type of aberrantly methylated

216 DNA sequence in glioma (Figure 5A, 5B, Supplementary Tables 6 and 7). In support

217 of this notion, experiments focused on the computational prediction of functional

218 elements confirmed the enrichment of canonical aberrant hypermethylation in

219 promoters and repressed sequences and revealed a completely different pattern for non-

220 canonical hypermethylation, one which is more closely associated with enhancers and

221 transcriptional regulation (Fisher's exact test; $\mathrm{p}<0.05$ ) (Figure 5-figure supplement

222 1).

Distinct functional role of canonical and non-canonical aberrant hypermethylation in glioma

226 To identify possible differences between the functional role of canonical and non-

227 canonical aberrant DNA hypermethylation in glioma we first ascribed CpG sites to

228 specific genes and then used HOMER to carry out gene ontology analyses of each

229 group of genes (see methods). Using this approach, we identified 1,921 genes

230 displaying canonical hypermethylation, 2,042 displaying non-canonical

231 hypermethylation and 938 displaying both types of aberrant hypermethylation (Figure

232 6A, Supplementary Tables 8, 9 and 10). As expected, GO analyses showed an

233 enrichment of development and differentiation processes in canonical genes [6] (Figure

234 6A, Supplementary Table 11). In contrast, non-canonical genes were strongly enriched

235 in cell signaling and protein processing pathways (Figure 6A, Supplementary Table

236 12).

237 To further investigate the functional role of canonical and non-canonical

238 hypermethylation in cancer, we compared our methylation data with previously

239 published gene expression data in the same type of tumor (see Materials and Methods).

240 Results showed that $681(31 \%)$ of the canonical and 585 (24\%) of the non-canonical

241 aberrantly hypermethylated genes were repressed in gliomas (Figure 6B).

242 Genomic distribution analysis of both types of aberrant hypermethylation confirmed the

243 enrichment of canonical hypermethylation in exons (chi-squared test, $\mathrm{p}<0.001$,

$244 \mathrm{OR}=1.79$ for general exons, $\mathrm{OR}=2.01$ for first exons), while non-canonical

245 hypermethylation was more frequent in introns (chi-squared test, $\mathrm{p}<0.001, \mathrm{OR}=1.7$ )

246 (Figure 6C). The genes frequently downregulated in glioma, SLC14A and the SMAD7,

247 represent two bona fide examples of this pattern of non-canonical aberrant

248 hypermethylation (Figure 6D, Figure 6-figure supplement 1). 

available under aCC-BY 4.0 International license.

249 Taken as a whole, these results indicate that both types of aberrant hypermethylation

250 have a similar effect on gene expression, but that they affect different types of genes and

251 gene regions. 


\section{Discussion}

253 During recent decades, it has largely been accepted that aberrant genomic DNA 254 methylation is a hallmark of cancer [10;11] and the best-known DNA methylation 255 alterations in tumors were the aberrant hypermethylation of $\mathrm{CpG}$ island promoters, and 256 global DNA hypomethylation. In both cases, the alterations were mostly attributed to 257 changes in the overall content and genomic distribution of $5 \mathrm{mC}[10 ; 11]$.

258 The vast majority of studies on DNA methylation and cancer have been based on the 259 sodium bisulfite modification of the genomic DNA, a chemical reaction that allows C 260 and $5 \mathrm{mC}$ to be distinguished by polymerase chain reaction [19]. However, this approach cannot distinguish between $5 \mathrm{mC}$ and 5-hydroxymethylcytosine $(5 \mathrm{hmC})$, the latter being a chemical modification of the cytosine first identified in bacteriophages in 1952 [54], and which has recently been found to be quite abundant in specific mammalian tissue [29]. $5 \mathrm{hmC}$ is synthesized from $5 \mathrm{mC}$ by the Ten-eleven Translocation (Tet) Enzymes, a family of proteins that can also catalyze the successive conversion of $5 \mathrm{hmC}$ to 5 formylcytosine and then to 5-carboxylcytosine, both of which can be transformed to unmodified $\mathrm{C}$ [40]. Although $5 \mathrm{hmC}$ was originally described as simply a demethylation intermediate of $C[16 ; 25]$, recent data suggest that this may be an epigenetic mark in its own right $[3 ; 22]$. Thus, as most previous studies did not distinguish between $5 \mathrm{mC}$ and $5 \mathrm{hmC}$, and it appears that DNA hydroxymethylation might play a specific role in cancer, in this work we aimed to re-evaluate changes in DNA methylation in cancer, paying special attention to the specific contribution of $5 \mathrm{hmC}$.

273 To identify the DNA regions affected by hydroxymethylation changes in cancer, we 274 first focused on four types of repeated DNA (LINE1, Sat $\alpha$, NBL2 and ALUYB8). 275 Among them, the LINE1 repeat is of particular interest because it contains almost 20\% 276 of the genomic $5 \mathrm{mC}$, and it has been proposed to be a surrogate of global DNA 277 methylation [51]. Our results confirmed that tumors lose $5 \mathrm{mC}$ at repeated DNA [7]. 278 However, the level of $5 \mathrm{hmC}$ at repeated DNA in healthy samples was very low and no 279 significant differences were observed compared to tumors, which indicates that the 280 global DNA hypo-hydroxymethylation previously observed in cancer $[23 ; 27 ; 28 ; 39]$ does not principally occur at repeated DNA. As changes in $5 \mathrm{hmC}$ at repeated DNA could not explain the global differences previously observed by mass spectrometry, we decided to study the possible contribution of single copy sequences. Genome-wide profiling of $5 \mathrm{mC}$ and $5 \mathrm{hmC}$ of healthy tissue identified a 10 -fold increase in abundance of $\mathrm{CpG}$ sites frequently hydroxymethylated in brain compared to colorectal tissue, 
286 providing evidence that the level of this epigenetic mark is highly tissue type287 dependent, and also that it is very abundant in the brain $[16 ; 24 ; 29 ; 32 ; 37 ; 44]$. 288 Moreover, $5 \mathrm{hmC}$ was enriched in regions with low $\mathrm{CpG}$ density and in introns in both 289 colorectal and brain tissue. As the $5 \mathrm{hmC}$ is enriched in different genomic regions, these 290 results support the notion that $5 \mathrm{hmC}$ is not simply a demethylation intermediate [1]. 291 Interestingly, 5hmC co-localized in regions marked with the activating histone PTM 292 H3K4me1. This histone mark has been previously associated with gene enhancers [20; 293 48], which suggests that DNA hydroxymethylation might play a role in gene regulation 294 in trans. Moreover, we have recently found an association between H3K4me1 and DNA 295 hypomethylation during aging in stem and differentiated cells [12], which may 296 represent an interesting link between aging and cancer at these genomic regions. 297 Colorectal tumors showed more changes with respect to $5 \mathrm{mC}$ than to $5 \mathrm{hmC}$. However, 298 in contrast, glioma presented more changes in $5 \mathrm{hmC}$ than in $5 \mathrm{mC}$, suggesting that the 299 dynamics of DNA methylation and hydroxymethylation in cancer is highly tumor-type 300 dependent. Moreover, the great number of hypo-hydroxymethylated single CpG sites in 301 glioma could explain the global differences previously observed by mass spectrometry $302[23 ; 27 ; 28 ; 39]$ and suggests that, in contrast to $5 \mathrm{mC}$, most DNA hypo303 hydroxymethylation in brain tumors occurs at single copy sequences.

304 The behavior of $5 \mathrm{hmC}$ led us to next identify two types of CpG sites aberrantly 305 hypermethylated in glioma: aberrantly hypermethylated $\mathrm{CpG}$ sites that showed no 306 changes in $5 \mathrm{hmC}$; and hypermethylated $\mathrm{CpG}$ sites that lose $5 \mathrm{hmC}$. The first of these 307 sites display similar chromatin signatures to previously described genes aberrantly 308 hypermethylated in cancer (i.e. enrichment in the repressive histone marks H3K9me3 309 and H3K27me3) [36; 38; 52]. In contrast, the second type of aberrantly 310 hypermethylated $\mathrm{CpG}$ sites were enriched in the activating histone PTMs H3K4me1, 311 H3K36me3, H3K79me2, H4K20me1 and H3K4me2. As these CpG sites present a 312 genuine chromatin signature which is different to the repressive chromatin signature of 313 the classical genes aberrantly hypermethylated in cancer $[36 ; 38 ; 52]$, we conclude that 314 they represent a novel $5 \mathrm{hmC}$-dependent non-canonical class of aberrant DNA 315 hypermethylation in glioma. As this gain in $5 \mathrm{mC}$ is inversely correlated with loss of $3165 \mathrm{hmC}$, it was not possible to identify this significant alteration in previous studies using 317 the classical sodium bisulfite-based technologies, since they are not able to distinguish 318 between the two chemical modifications. 
319 Aberrant DNA hypermethylation in cancer was discovered more than 30 years ago, but

320 the underlying molecular mechanisms are still poorly understood. For example, it has

321 been proposed that genes enriched in bivalent histone modifications (H3K4me3 and

$322 \mathrm{H} 3 \mathrm{~K} 27 \mathrm{me} 3$ ) and polycomb group proteins during embryo development are prone to

323 become aberrantly hypermethylated in cancer [36; 38; 52] but the molecular basis of

324 this is unknown. Our data suggest that tumor cells might in fact acquire aberrant DNA

325 methylation through various different pathways. Moreover, in the case of the non-

326 canonical hypermethylation, the previous loss of $5 \mathrm{hmC}$ suggests that aberrant

327 hypermethylation at these DNA regions could be due to an attempt by the cell to reverse

328 or repair the loss of $5 \mathrm{hmC}$ at functionally sensible loci. This possibility is supported by

329 the fact that the non-canonical aberrant hypermethylation described here seems to play

330 an important role in gene regulation. Intriguingly, $5 \mathrm{hmC}$ at gene promoters has also

331 been proposed to protect from aberrant hypermethylation in colorectal cancer [50].

332 Thus, although it seems that $5 \mathrm{hmC}$ plays an important role in the regulation of the DNA

333 methylation changes in cancer, more research is needed to fully understand its role.

334 The non-canonical aberrant hypermethylation described here seems to have a similar 335 overall effect on gene expression as classical canonical hypermethylation, although the

336 type of genes and the genomic regions affected are very different. Previous research has

337 shown that the repression of developmental genes affected by canonical aberrant 338 hypermethylation promotes tumorigenesis [6]. However, the possible functional role of 339 disruption of cell signaling and protein processing pathways affected by the non340 canonical hypermethylation described in this study remains to be elucidated. Future 341 research is thus needed to address this issue, and to determine whether the two types of 342 aberrant DNA hypermethylation have distinct functional roles in cancer. 


\section{Materials and methods}

$345 \quad$ Normal samples and primary tumors

346 The colon and brain samples analyzed in this study were collected at the Hospital

347 Universitario Central de Asturias (HUCA), the Hospital Virgen de la Salud, Toledo, and

348 the Hospital Universitario Puerta de Hierro, Madrid. The samples studied comprised 72

349 normal colons, 13 normal brains, 72 colorectal primary tumors and 54 glioblastomas.

350 The study was approved by the Clinical Research Ethics Committee and all the

351 individuals involved provided written informed consent.

Pyrosequencing assays

$3545 \mathrm{mC}$ and $5 \mathrm{hmC}$ patterns at repetitive sequences (LINE1, ALUBY8, Sat $\alpha$ and NBL2)

355 were analyzed by pyrosequencing using previously described primers [49]. To calculate

$3565 \mathrm{hmC}$ levels, each sample was analyzed using two methods performed in parallel; an

357 oxidative bisulfite conversion (oxBS) and a bisulfite-only conversion (BS), in

358 accordance with the TrueMethyl ${ }^{\circledR}$ Array Kit User Guide (CEGX, Version 2) with some

359 modifications. Briefly, DNA samples were cleaned using Agencourt AMPure XP

360 (Beckman Coulter) then oxidated with $1 \mu \mathrm{L}$ of a KRuO4 (Alpha Aeser) solution (375

$361 \mathrm{mM}$ in $0.3 \mathrm{M} \mathrm{NaOH}$ ), after which bisulfite conversion was performed using EpiTect

362 bisulfite kit (Qiagen $\left.{ }^{\circledR}\right)$.

363 After PCR amplification of the region of interest in oxBS and BS samples,

364 pyrosequencing was performed using PyroMark Q24 reagents, and vacuum prep

365 workstation, equipment and software (Qiagen ${ }^{\circledR}$ ). 5hmC levels were obtained when

366 methylation values of oxBS samples (represents true $5 \mathrm{mC}$ ) were subtracted from their

367 corresponding BS treated pairs (the latter representing $5 \mathrm{mC}+5 \mathrm{hmC}$ ).

369 Genome-wide DNA methylation analysis with high-density arrays

370 Microarray-based DNA methylation profiling was performed with the

371 HumanMethylation 450 BeadChip [2]. Oxidative bisulfite (oxBS) and bisulfite-only

372 (BS) conversion was performed using the TrueMethyl® protocol for $450 \mathrm{~K}$ analysis

373 (Version 1.1, CEGX) following the manufacturer's recommended procedures.

374 Processed DNA samples were then hybridized to the BeadChip (Illumina), following

375 the Illumina Infinium HD Methylation Protocol. Genotyping services were provided by

376 the Spanish Centro Nacional de Genotipado (CEGEN-ISCIII) (www.cegen.org). DNA 
377 methylation data were downloaded from ArrayExpress accession numbers E-MTAB-

3786003 (brain) and E-MTAB-xxx (colon).

379

380 HumanMethylation450 BeadChip data preprocessing

381 Raw IDAT files were processed using the R/Bioconductor package minfi [15] (version

382 1.14.0), implementing the SWAN algorithm [35] to correct for differences in the

383 microarray probe designs. No background correction or control probe normalization

384 was applied. Probes where at least two samples had detection p-values $>0.01$, and 385 samples where at least 5500 probes had detection $p$-values $>0.01$ were filtered out. M-

386 values and beta values were computed as the final step in the preprocessing procedure.

387 In line with a previously published methodology [5], M-values were used for the

388 statistical analyses and beta values for effect size thresholding, visualization and report 389 generation.

390

\section{Batch effect correction}

392 In order to detect whether there was any batch effect associated with technical factors, 393 the visualization technique of multidimensional scaling (MDS) was employed to 394 highlight any strange interaction affecting the different samples. Where necessary, 395 posterior adjustment of the samples was performed by means of the SVA method [31] 396 implemented in the R/Bioconductor sva package (version 3.14.0).

\section{Computation of hydroxymethylation levels}

399 Beta values from oxBS samples were subtracted from their corresponding BS treated 400 pairs, generating an artificial dataset representing the level of $5 \mathrm{hmC}$ for each probe and 401 sample as per a previously published methodology [45]. One further dataset was created 402 to represent the $5 \mathrm{mC}$ levels using beta values from oxBS samples.

404 Detection of differentially methylated probes

405 Differential methylation and hydroxymethylation of an individual probe was determined 406 by a moderated t-test implemented in the R/Bioconductor package limma [43]. A linear 407 model, with methylation or hydroxymethylation levels as response and the sample 408 group (normal/tumoral) as the principal covariate of interest, was then fitted to the 409 methylation or hydroxymethylation data. Surrogate Variables generated using SVA 410 were also included in the model definition, but excluding those found to be correlated to 
411 the phenotype of interest. $\mathrm{P}$ values were corrected for multiple testing using the

412 Benjamini-Hochberg method for controlling false discovery rate (FDR). An FDR

413 threshold of 0.001 was employed to determine differentially methylated and

414 hydroxymethylated probes. Additionally, these probes were filtered according to their

415 effect size, keeping only those probes with methylation or hydroxymethylation changes

416 between-groups which exceeded the median of all differences for the same comparison.

417 The probes without no significant $5 \mathrm{hmC}$ signal on control samples were filtered out

418 from the set of hypo-hydroxymethylated probes in glioma.

419

Identification of hydroxymethylated probes

421 In order to identify those probes representing the regions where the $5 \mathrm{hmC}$ mark is

422 located, a differential hydroxymethylation analysis was performed as described 423 previously [14] using a dataset containing both oxBS and BS versions of the control 424 samples. Probes with significant differences in beta values between the BS and oxBS 425 samples were considered to be enriched for the 5hmC mark. An FDR threshold of 0.001 426 was employed. No filtering on effect size was applied in this case.

428 Histone enrichment analysis

429 In order to analyze the enrichment of histone marks on a subset of probes, we used the 430 information contained in the UCSC Genome Browser Broad Histone track from the 431 ENCODE Project. Histone mark peaks were downloaded for every combination of cell 432 line and antibody. For each track, a $2 \times 2$ contingency table was built to represent the 433 partition of the whole set of possible probes in the microarray with respect to the 434 membership of the subset of interest and the overlap between the probes and the histone 435 peaks. A Fisher's exact test was used to determine whether there was significant 436 enrichment of the selected histone mark for the subset of interest. P-values were 437 adjusted for multiple comparisons using the Benjamini-Hochberg method for 438 controlling FDR. A significance level of 0.05 was used to determine whether the given 439 combination of histone mark and cell line presented a significant change in proportion. 440 Additionally, the base-2 logarithm of the Odds Ratio (OR) was used as a measure of 441 effect size. 
444 Data from the BROAD ChromHMM Project were downloaded from the UCSC Genome

445 Browser site. Each of the tracks comprising this dataset represents a different 446 segmentation generated by a Hidden Markov Model (HMM) using Chip-Seq signals

447 from the Broad Histone Project as inputs. The segmentations were later curated and 448 labelled according to their functional status [8;9]. In order to detect any significant 449 enrichment in the proportion of probes in a given subset of interest belonging to one 450 functional category, an analysis strategy similar to the one employed for the detection of 451 histone enrichment was performed. In this case, a $2 \times 2$ contingency table was built using segments of a given functional status rather than antibodies. A Fisher's exact test was employed, and significant combinations were detected using a FDR threshold of 0.05

454 (Benjamini-Hochberg procedure). Again, the base-2 logarithm of the OR was used as a measure of effect size.

\section{Genomic region analysis}

458 The probes in the microarray were assigned to a genomic region according to their 459 position relative to the transcript information extracted from the R/Bioconductor 460 package TxDb.Hsapiens.UCSC.hg19.knownGene (package version 3.1.2). A probe was said to be in a promoter region if it was located in a region up to $2 \mathrm{~kb}$ upstream of the transcription start site (TSS) of any given transcript. Similarly, a set of mutually exclusive regions were defined inside the transcripts, namely 5UTR, 3UTR, First Exon, Exon and Intron. A probe could only belong to one category, hence if the location of a probe overlapped with two or more regions in different transcripts, it was assigned to the region with a higher level of precedence (i.e. in the order stated above, earlier mention indicates higher precedence). If a probe was not assigned to any of these special regions, it was labelled by default as Intergenic. A contingency table was built for each of the subsets, partitioning the whole set of probes according to membership to a given category and the subset of interest. A Pearson's $\chi^{2}$ test was used to determine whether there was any significant change in proportion between the number of probes marked as belonging to a given region inside and outside the subset of interest. A significance level of 0.05 was employed, and effect size measured by OR.

CGI status analysis

476 Similar to the genomic region analysis, probes were labelled according to their relative

477 position to CpG-islands (CGIs), the locations of which were obtained from the 
478 R/Bioconductor package FDb.InfiniumMethylation.hg19 (package version 2.2.0). The 479 generation procedure of these CGIs is described by [53], i.e. 'CpG shores' were defined 480 as the $2 \mathrm{kbp}$ regions flanking a CGI. 'CpG shelves' were defined as the $2 \mathrm{kbp}$ regions 481 either upstream of or downstream from each $\mathrm{CpG}$ shore. Probes not belonging to any of 482 the regions thus far mentioned were assigned to the special category 'non-CGI' with 483 each probe being assigned to only one of the categories. A $4 \times 2$ contingency table was 484 constructed for each subset of probes in order to study the association between the given 485 subset and the different CGI categories. A $\chi 2$ test was used to determine whether any of 486 the categories had a significant association with the given subset. For each of the CGI 487 status levels, a $2 \times 2$ contingency table was defined and another $\chi 2$ test used to 488 independently evaluate the association of the given subset with each status level, a 489 significance level of 0.05 being employed for all tests. Effect size was reported as the 490 OR for each of the individual tests.

Analysis of CpG density

493 For each of the probes in the HumanMethylation450 microarray, CpG density was 494 measured as the number of CG 2-mers present divided by the number which would be 495 theoretically possible in a $2 \mathrm{kbp}$ window with the $\mathrm{CpG}$ under study at its centre. A 496 Wilcoxon non-parametric test was used to determine if any significant difference 497 existed between the $\mathrm{CpG}$ density of each subset of interest and that of the array probes 498 in the background. A significance level of 0.05 was employed for all tests. Effect size was measured using Cliff's Delta (D).

Gap distance analysis

502 Distance to both the centromere and telomere was measured for each of the probes in 503 the HumanMethylation450 microarray. In order to find significant differences between

504 the probes within the subset of interest and those in the background, a Wilcoxon nonparametric test was used. Once again, a significance level of 0.05 was employed for all tests, and Cliff's Delta (D) was used as a measure of effect size.

Microarray background correction

509 Although it is sometimes referred to as a genome-wide solution, the 510 HumanMethylation450 BeadChip only covers a fraction of the entire genome. In its $51127 \mathrm{~K}$ predecessor, the probes were mainly located at gene promoter regions, while the 
512 newer HumanMethylation450 BeadChip additionally includes probes located inside

513 genes and in intergenic regions [4].

514 The irregular distribution of probes can however lead to unwanted biases when studying

515 whether a selected subset of probes is enriched with respect to any functional or clinical

516 mark. For this reason, here a reference to the background distribution of features was

517 included in all statistical tests performed in order to prevent our conclusions from being

518 driven by the irregular distribution of probes. In qualitative tests (CGI status, genomic

519 region, or histone mark enrichment), the contingency matrix was built to represent the

520 background distribution of the microarray. In quantitative tests ( $\mathrm{CpG}$ density, distance

521 to centromeres and telomeres) the corresponding metric was compared between the

522 subset of interest and the remaining probes in the microarray. Thus, any significant

523 result would indicate a departure from the fixed background distribution and ignore any

524 bias inherent in the test.

526 Gene ontology analysis and annotation

527 Probe sets were converted to gene sets by using the annotation information from the 528 R/Bioconductor package TxDb.Hsapiens.UCSC.hg19.knownGene (version 3.1.2). A 529 probe was assigned to a gene if the probe was contained within the overlap of all the 530 genomic regions represented by the different transcripts belonging to that gene, or in a $5312 \mathrm{kbp}$ region upstream of the corresponding TSS. Probes converted this way can be 532 assigned to one or more genes, or to zero (i.e. intergenic probes).

533 After gene conversion, each subset of interest was analyzed using the HOMER software 534 tool [18]. The software was configured to use the whole set of genes represented in the 535 HumanMethylation450 architecture as a background. HOMER tested the genes in each 536 subset of interest against 21 different databases, including the Gene Ontology (GO) 537 Biological Process, Molecular Function and Cellular Component ontologies, as well as 538 KEGG and Reactome pathway databases, among many others.

\section{$540 \quad$ Circular visualization and track smoothing}

541 In order to plot the $\mathrm{CpG}$ and histone peak information on the circular genome-wide and example graphs, smoothing was applied to the data. $\mathrm{CpG}$ enrichment information for canonical and non-canonical hypermethylation was generated by partitioning the

544 genome into intervals of $10 \mathrm{kbp}$ and assigning to each a score corresponding to the average coverage of the selected CpGs in the interval. 
547 Whole-genome bisulfite sequencing (WGBS) datasets

548 Supplementary data referenced in [42] was used as a validation dataset in glioblastoma.

549 Previously processed data in the form of quantified methylation for each $\mathrm{CpG}$ measured

550 in both strands of the genome was downloaded and filtered. Only methylation measures

551 from $\mathrm{CpGs}$ having a total read count higher than 10 were retained.

552 The resulting dataset comprised only two samples (normal and tumoral), so a

553 descriptive strategy was used to distinguish the different types of probes according to

554 their methylation status. Hydroxymethylated probes were identified as those having a

$5555 \mathrm{hmC}$ measure higher than 0.1. Differentially methylated probes were defined as those

556 having an absolute difference in their methylation values, between the control and

557 tumor samples, higher than a given threshold ( 0.2 for $5 \mathrm{mC}$ and 0.1 for $5 \mathrm{hmC}$ ).

558 The validation datasets may contain either one or two methylation measures for each

$559 \mathrm{CpG}$ in the genome as they measure methylation in both strands. Strand-agnostic CpG

560 regions representing the $\mathrm{CpG}$ dinucleotides with at least one measure were defined in

561 order to compute the degree of intersection between the WGBS and methylation arrays

562 results.

563

564 TCGA expression datasets

565 In order to analyze changes in gene expression, samples of glioblastoma multiforme 566 (GBM) were selected from among the data generated by the TCGA Research Network

567 (http://cancergenome.nih.gov). Expression Level-3 pre-processed data was obtained for

568572 GBM samples (10 controls and 562 tumors). The moderated t-test approach in the

$569 \mathrm{R} /$ Bioconductor package limma was used to assess the differential expression status of

570 each gene in the TCGA datasets. The normalized expression ratio in the TCGA datasets

571 was used as the response variable, and the sample group (normal/tumoral) as the

572 covariate of interest. No adjustment for possible confounders was performed in this

573 case. An FDR threshold of 0.001 was used to correct for multiple hypotheses. No

574 filtering on effect size was applied in this case.

575

576 Data analysis workflow

577 All the necessary steps for upstream and downstream analyses were defined and

578 implemented using the Snakemake tool [26], which helps data scientists to generate a 

available under aCC-BY 4.0 International license.

579 reproducible and inherently parallel processing pipeline. Individual workflow tasks

580 were implemented in $\mathrm{R}$ (version 3.2.2) and Python (version 3.4.3).

581 


\section{Acknowledgments}

583 We thank Ronnie Lendrum for editorial assistance. We also thank the Tumor Bank of 584 the Hospital Virgen de la Salud (BioB-HVS, Toledo, Spain) for providing tumor 585 samples. This work has been financially supported by: the Plan Nacional de I+D+I 586 2013-2016/FEDER (PI15/00892 to M.F.F. and A.F.F.); the ISCIII-Subdirección 587 General de Evaluación y Fomento de la Investigación, and the Plan Nacional de I+D+I 588 2008-2011/FEDER (CP11/00131 to A.F.F.); IUOPA (to G.F.B. and M.S); the 589 Fundación Científica de la AECC (to R.G.U.); the Fundación Ramón Areces (to M.F.F); 590 FICYT (to E.G.T., M.G.G. and A.C.); and the Asturias Regional Government 591 (GRUPIN14-052 to M.F.F.). Work in P.M. lab is supported by the European Research 592 Council (CoG-2014-646903), the Spanish Ministry of Economy-Competitiveness (SAF593 SAF2013-43065), the Obra Social La Caixa-Fundaciò Josep Carreras, and the 594 Generalitat de Catalunya. P.M. is an investigator in the Spanish Cell Therapy 595 cooperative network (TERCEL). The IUOPA is supported by the Obra Social Cajastur596 Liberbank, Spain.

599 Competing interests: The authors declare that no competing interests exist. 
601

602

603

604

605

606

607

608

609

610

611

612

613

614

615

616

617

618

619

620

621

622

623

624

625

626

627

628

629

630

631

632

633

634

635

636

637

638

639

640

641

642

643

644

645

646

647

648

\section{References}

[1] M. Bachman, S. Uribe-Lewis, X. Yang, M. Williams, A. Murrell, and S. Balasubramanian, 5-Hydroxymethylcytosine is a predominantly stable DNA modification. Nat Chem 6 (2014) 1049-55.

[2] M. Bibikova, B. Barnes, C. Tsan, V. Ho, B. Klotzle, J.M. Le, D. Delano, L. Zhang, G.P. Schroth, K.L. Gunderson, J.B. Fan, and R. Shen, High density DNA methylation array with single CpG site resolution. Genomics 98 (2011) 288-95.

[3] C.G. Chapman, C.J. Mariani, F. Wu, K. Meckel, F. Butun, A. Chuang, J. Madzo, M.B. Bissonette, J.H. Kwon, and L.A. Godley, TET-catalyzed 5hydroxymethylcytosine regulates gene expression in differentiating colonocytes and colon cancer. Sci Rep 5 (2015) 17568.

[4] S. Dedeurwaerder, M. Defrance, E. Calonne, H. Denis, C. Sotiriou, and F. Fuks, Evaluation of the Infinium Methylation 450K technology. Epigenomics 3 (2011) 771-84.

[5] P. Du, X. Zhang, C.C. Huang, N. Jafari, W.A. Kibbe, L. Hou, and S.M. Lin, Comparison of Beta-value and M-value methods for quantifying methylation levels by microarray analysis. BMC Bioinformatics 11 (2010) 587.

[6] H. Easwaran, S.E. Johnstone, L. Van Neste, J. Ohm, T. Mosbruger, Q. Wang, M.J. Aryee, P. Joyce, N. Ahuja, D. Weisenberger, E. Collisson, J. Zhu, S. Yegnasubramanian, W. Matsui, and S.B. Baylin, A DNA hypermethylation module for the stem/progenitor cell signature of cancer. Genome Res 22 (2012) 837-49.

[7] M. Ehrlich, DNA hypomethylation in cancer cells. Epigenomics 1 (2009) 239-59.

[8] J. Ernst, and M. Kellis, Discovery and characterization of chromatin states for systematic annotation of the human genome. Nat Biotechnol 28 (2011) 817-25.

[9] J. Ernst, P. Kheradpour, T.S. Mikkelsen, N. Shoresh, L.D. Ward, C.B. Epstein, X. Zhang, L. Wang, R. Issner, M. Coyne, M. Ku, T. Durham, M. Kellis, and B.E. Bernstein, Mapping and analysis of chromatin state dynamics in nine human cell types. Nature 473 (2011) 43-9.

[10] M. Esteller, Aberrant DNA methylation as a cancer-inducing mechanism. Annu Rev Pharmacol Toxicol 45 (2005) 629-56.

[11] A.P. Feinberg, and B. Tycko, The history of cancer epigenetics. Nat Rev Cancer 4 (2004) 143-53.

[12] A.F. Fernandez, G.F. Bayon, R.G. Urdinguio, E.G. Torano, M.G. Garcia, A. Carella, S. Petrus-Reurer, C. Ferrero, P. Martinez-Camblor, I. Cubillo, J. GarciaCastro, J. Delgado-Calle, F.M. Perez-Campo, J.A. Riancho, C. Bueno, P. Menendez, A. Mentink, K. Mareschi, F. Claire, C. Fagnani, E. Medda, V. Toccaceli, S. Brescianini, S. Moran, M. Esteller, A. Stolzing, J. de Boer, L. Nistico, M.A. Stazi, and M.F. Fraga, H3K4me1 marks DNA regions hypomethylated during aging in human stem and differentiated cells. Genome Res 25 (2014) 27-40.

[13] G. Ficz, M.R. Branco, S. Seisenberger, F. Santos, F. Krueger, T.A. Hore, C.J. Marques, S. Andrews, and W. Reik, Dynamic regulation of 5hydroxymethylcytosine in mouse ES cells and during differentiation. Nature 473 (2011) 398-402.

[14] S.F. Field, D. Beraldi, M. Bachman, S.K. Stewart, S. Beck, and S. Balasubramanian, Accurate measurement of 5-methylcytosine and 5- 
665

666

667

668

669

670

671

672

673

674

675

676

677

678

679

680

681

682

683

684

685

686

687

688

689

690

691

692

693

694

695

696

697

698

hydroxymethylcytosine in human cerebellum DNA by oxidative bisulfite on an array (OxBS-array). PLoS One 10 (2015) e 0118202.

[15] J.P. Fortin, A. Labbe, M. Lemire, B.W. Zanke, T.J. Hudson, E.J. Fertig, C.M. Greenwood, and K.D. Hansen, Functional normalization of 450k methylation array data improves replication in large cancer studies. Genome Biol 15 (2014) 503.

[16] D. Globisch, M. Munzel, M. Muller, S. Michalakis, M. Wagner, S. Koch, T. Bruckl, M. Biel, and T. Carell, Tissue distribution of 5-hydroxymethylcytosine and search for active demethylation intermediates. PLoS One 5 (2010) e15367.

[17] M.C. Haffner, A. Chaux, A.K. Meeker, D.M. Esopi, J. Gerber, L.G. Pellakuru, A. Toubaji, P. Argani, C. Iacobuzio-Donahue, W.G. Nelson, G.J. Netto, A.M. De Marzo, and S. Yegnasubramanian, Global 5-hydroxymethylcytosine content is significantly reduced in tissue stem/progenitor cell compartments and in human cancers. Oncotarget 2 (2011) 627-37.

[18] S. Heinz, C. Benner, N. Spann, E. Bertolino, Y.C. Lin, P. Laslo, J.X. Cheng, C. Murre, H. Singh, and C.K. Glass, Simple combinations of lineage-determining transcription factors prime cis-regulatory elements required for macrophage and B cell identities. Mol Cell 38 (2010) 576-89.

[19] J.G. Herman, J. Jen, A. Merlo, and S.B. Baylin, Hypermethylation-associated inactivation indicates a tumor suppressor role for p15INK4B. Cancer Res 56 (1996) 722-7.

[20] G.C. Hon, C.X. Song, T. Du, F. Jin, S. Selvaraj, A.Y. Lee, C.A. Yen, Z. Ye, S.Q. Mao, B.A. Wang, S. Kuan, L.E. Edsall, B.S. Zhao, G.L. Xu, C. He, and B. Ren, $5 \mathrm{mC}$ oxidation by Tet 2 modulates enhancer activity and timing of transcriptome reprogramming during differentiation. Mol Cell 56 (2014) 286-97.

[21] S. Ito, A.C. D'Alessio, O.V. Taranova, K. Hong, L.C. Sowers, and Y. Zhang, Role of Tet proteins in $5 \mathrm{mC}$ to $5 \mathrm{hmC}$ conversion, ES-cell self-renewal and inner cell mass specification. Nature 466 (2010) 1129-33.

[22] D. Jiang, Y. Zhang, R.P. Hart, J. Chen, K. Herrup, and J. Li, Alteration in 5hydroxymethylcytosine-mediated epigenetic regulation leads to Purkinje cell vulnerability in ATM deficiency. Brain 138 (2015) 3520-36.

[23] S.G. Jin, Y. Jiang, R. Qiu, T.A. Rauch, Y. Wang, G. Schackert, D. Krex, Q. Lu, and G.P. Pfeifer, 5-Hydroxymethylcytosine is strongly depleted in human cancers but its levels do not correlate with IDH1 mutations. Cancer Res 71 (2011) 7360-5.

[24] T. Khare, S. Pai, K. Koncevicius, M. Pal, E. Kriukiene, Z. Liutkeviciute, M. Irimia, P. Jia, C. Ptak, M. Xia, R. Tice, M. Tochigi, S. Morera, A. Nazarians, D. Belsham, A.H. Wong, B.J. Blencowe, S.C. Wang, P. Kapranov, R. Kustra, V. Labrie, S. Klimasauskas, and A. Petronis, 5-hmC in the brain is abundant in synaptic genes and shows differences at the exon-intron boundary. Nat Struct Mol Biol 19 (2012) 1037-43.

[25] M. Klug, S. Schmidhofer, C. Gebhard, R. Andreesen, and M. Rehli, 5Hydroxymethylcytosine is an essential intermediate of active DNA demethylation processes in primary human monocytes. Genome Biol 14 (2013) R46.

[26] J. Koster, and S. Rahmann, Snakemake--a scalable bioinformatics workflow engine. Bioinformatics 28 (2012) 2520-2.

[27] T.F. Kraus, D. Globisch, M. Wagner, S. Eigenbrod, D. Widmann, M. Munzel, M. Muller, T. Pfaffeneder, B. Hackner, W. Feiden, U. Schuller, T. Carell, and H.A. Kretzschmar, Low values of 5-hydroxymethylcytosine (5hmC), the "sixth base," 
are associated with anaplasia in human brain tumors. Int J Cancer 131 (2015) 1577-90.

[28] T.F. Kraus, G. Kolck, A. Greiner, K. Schierl, V. Guibourt, and H.A. Kretzschmar, Loss of 5-hydroxymethylcytosine and intratumoral heterogeneity as an epigenomic hallmark of glioblastoma. Tumour Biol 36 (2012) 8439-46.

[29] S. Kriaucionis, and N. Heintz, The nuclear DNA base 5-hydroxymethylcytosine is present in Purkinje neurons and the brain. Science 324 (2009) 929-30.

[30] Y. Kudo, K. Tateishi, K. Yamamoto, S. Yamamoto, Y. Asaoka, H. Ijichi, G. Nagae, H. Yoshida, H. Aburatani, and K. Koike, Loss of 5hydroxymethylcytosine is accompanied with malignant cellular transformation. Cancer Sci 103 (2012) 670-6.

[31] J.T. Leek, and J.D. Storey, Capturing heterogeneity in gene expression studies by surrogate variable analysis. PLoS Genet 3 (2007) 1724-35.

[32] W. Li, and M. Liu, Distribution of 5-hydroxymethylcytosine in different human tissues. J Nucleic Acids 2011 (2011) 870726.

[33] C.G. Lian, Y. Xu, C. Ceol, F. Wu, A. Larson, K. Dresser, W. Xu, L. Tan, Y. Hu, Q. Zhan, C.W. Lee, D. Hu, B.Q. Lian, S. Kleffel, Y. Yang, J. Neiswender, A.J. Khorasani, R. Fang, C. Lezcano, L.M. Duncan, R.A. Scolyer, J.F. Thompson, H. Kakavand, Y. Houvras, L.I. Zon, M.C. Mihm, Jr., U.B. Kaiser, T. Schatton, B.A. Woda, G.F. Murphy, and Y.G. Shi, Loss of 5-hydroxymethylcytosine is an epigenetic hallmark of melanoma. Cell 150 (2012) 1135-46.

[34] C. Liu, L. Liu, X. Chen, J. Shen, J. Shan, Y. Xu, Z. Yang, L. Wu, F. Xia, P. Bie, Y. Cui, X.W. Bian, and C. Qian, Decrease of 5-hydroxymethylcytosine is associated with progression of hepatocellular carcinoma through downregulation of TET1. PLoS One 8 (2013) e62828.

[35] J. Maksimovic, L. Gordon, and A. Oshlack, SWAN: Subset-quantile within array normalization for illumina infinium HumanMethylation450 BeadChips. Genome Biol 13 (2012) R44.

[36] K.M. McGarvey, J.A. Fahrner, E. Greene, J. Martens, T. Jenuwein, and S.B. Baylin, Silenced tumor suppressor genes reactivated by DNA demethylation do not return to a fully euchromatic chromatin state. Cancer Res 66 (2006) 3541-9.

[37] C.E. Nestor, R. Ottaviano, J. Reddington, D. Sproul, D. Reinhardt, D. Dunican, E. Katz, J.M. Dixon, D.J. Harrison, and R.R. Meehan, Tissue type is a major modifier of the 5-hydroxymethylcytosine content of human genes. Genome Res 22 (2012) 467-77.

[38] J.E. Ohm, K.M. McGarvey, X. Yu, L. Cheng, K.E. Schuebel, L. Cope, H.P. Mohammad, W. Chen, V.C. Daniel, W. Yu, D.M. Berman, T. Jenuwein, K. Pruitt, S.J. Sharkis, D.N. Watkins, J.G. Herman, and S.B. Baylin, A stem celllike chromatin pattern may predispose tumor suppressor genes to DNA hypermethylation and heritable silencing. Nat Genet 39 (2007) 237-42.

[39] B.A. Orr, M.C. Haffner, W.G. Nelson, S. Yegnasubramanian, and C.G. Eberhart, Decreased 5-hydroxymethylcytosine is associated with neural progenitor phenotype in normal brain and shorter survival in malignant glioma. PLoS One 7 (2012) e41036.

[40] N. Plongthongkum, D.H. Diep, and K. Zhang, Advances in the profiling of DNA modifications: cytosine methylation and beyond. Nat Rev Genet 15 (2014) 64761.

[41] E.L. Putiri, R.L. Tiedemann, J.J. Thompson, C. Liu, T. Ho, J.H. Choi, and K.D. Robertson, Distinct and overlapping control of 5-methylcytosine and 5- 
hydroxymethylcytosine by the TET proteins in human cancer cells. Genome Biol 15 (2014) R81.

[42] E.-A. Raiber, D. Beraldi, S. Martinez Cuesta, G.R. McInroy, Z. Kingsbury, J. Becq, T. James, M. Lopes, K. Allinson, S. Field, S. Humphray, T. Santarius, C. Watts, D. Bentley, and S. Balasubramanian, Base resolution maps reveal the importance of 5-hydroxymethylcytosine in a human glioblastoma. npj Genomic Medicine 2 (2017) 6.

[43] M.E. Ritchie, B. Phipson, D. Wu, Y. Hu, C.W. Law, W. Shi, and G.K. Smyth, limma powers differential expression analyses for RNA-sequencing and microarray studies. Nucleic Acids Res 43 (2015) e47.

[44] C.X. Song, K.E. Szulwach, Y. Fu, Q. Dai, C. Yi, X. Li, Y. Li, C.H. Chen, W. Zhang, X. Jian, J. Wang, L. Zhang, T.J. Looney, B. Zhang, L.A. Godley, L.M. Hicks, B.T. Lahn, P. Jin, and C. He, Selective chemical labeling reveals the genome-wide distribution of 5-hydroxymethylcytosine. Nat Biotechnol 29 (2011) 68-72.

[45] S.K. Stewart, T.J. Morris, P. Guilhamon, H. Bulstrode, M. Bachman, S. Balasubramanian, and S. Beck, oxBS-450K: a method for analysing hydroxymethylation using 450K BeadChips. Methods 72 (2015) 9-15.

[46] M. Sun, C.X. Song, H. Huang, C.A. Frankenberger, D. Sankarasharma, S. Gomes, P. Chen, J. Chen, K.K. Chada, C. He, and M.R. Rosner, HMGA2/TET1/HOXA9 signaling pathway regulates breast cancer growth and metastasis. Proc Natl Acad Sci U S A 110 (2013) 9920-5.

[47] M. Tahiliani, K.P. Koh, Y. Shen, W.A. Pastor, H. Bandukwala, Y. Brudno, S. Agarwal, L.M. Iyer, D.R. Liu, L. Aravind, and A. Rao, Conversion of 5methylcytosine to 5-hydroxymethylcytosine in mammalian DNA by MLL partner TET1. Science 324 (2009) 930-5.

[48] E.G. Torano, G.F. Bayon, A. Del Real, M.I. Sierra, M.G. Garcia, A. Carella, T. Belmonte, R.G. Urdinguio, I. Cubillo, J. Garcia-Castro, J. Delgado-Calle, F.M. Perez-Campo, J.A. Riancho, M.F. Fraga, and A.F. Fernandez, Age-associated hydroxymethylation in human bone-marrow mesenchymal stem cells. J Transl Med 14 (2016) 207.

[49] R.G. Urdinguio, G.F. Bayon, M. Dmitrijeva, E.G. Torano, C. Bravo, M.F. Fraga, L. Bassas, S. Larriba, and A.F. Fernandez, Aberrant DNA methylation patterns of spermatozoa in men with unexplained infertility. Hum Reprod 30 (2015) 1014-28.

[50] S. Uribe-Lewis, R. Stark, T. Carroll, M.J. Dunning, M. Bachman, Y. Ito, L. Stojic, S. Halim, S.L. Vowler, A.G. Lynch, B. Delatte, E.J. de Bony, L. Colin, M. Defrance, F. Krueger, A.L. Silva, R. Ten Hoopen, A.E. Ibrahim, F. Fuks, and A. Murrell, 5-hydroxymethylcytosine marks promoters in colon that resist DNA hypermethylation in cancer. Genome Biol 16 (2015) 69.

[51] D.J. Weisenberger, M. Campan, T.I. Long, M. Kim, C. Woods, E. Fiala, M. Ehrlich, and P.W. Laird, Analysis of repetitive element DNA methylation by MethyLight. Nucleic Acids Res 33 (2005) 6823-36.

[52] M. Widschwendter, H. Fiegl, D. Egle, E. Mueller-Holzner, G. Spizzo, C. Marth, D.J. Weisenberger, M. Campan, J. Young, I. Jacobs, and P.W. Laird, Epigenetic stem cell signature in cancer. Nat Genet 39 (2007) 157-8.

[53] H. Wu, B. Caffo, H.A. Jaffee, R.A. Irizarry, and A.P. Feinberg, Redefining CpG islands using hidden Markov models. Biostatistics 11 (2010) 499-514.

[54] G.R. Wyatt, and S.S. Cohen, A new pyrimidine base from bacteriophage nucleic acids. Nature 170 (1952) 1072-3. 
798

799

800

801

802

803

804
[55] H. Yang, Y. Liu, F. Bai, J.Y. Zhang, S.H. Ma, J. Liu, Z.D. Xu, H.G. Zhu, Z.Q. Ling, D. Ye, K.L. Guan, and Y. Xiong, Tumor development is associated with decrease of TET gene expression and 5-methylcytosine hydroxylation. Oncogene 32 (2013) 663-9. 
805

806

807

808

809

810

811

812

813

814

815

816

817

818

819

820

821

822

823

824

825

826

827

828

829

830

831

832

833

834

835

836

837

838

839

\section{Figure legends}

Figure $1.5 \mathrm{mC}$ and $5 \mathrm{hmC}$ levels at repetitive DNA sequences in glioma and CRC. $5 \mathrm{mC}(\mathrm{A})$ and $5 \mathrm{hmC}(\mathrm{B})$ values of several repetitive regions (AluYb8, LINE-1, NBL-2, and Sat-alpha) measured by bisulfite pyrosequencing in controls and glioma (left panels) and $\mathrm{CRC}$ (right panels). Individual $\mathrm{CpG}$ site values for each repeat are displayed. P-values are shown.

\section{Figure 2. Characterization of DNA $5 \mathrm{hmC}$ in normal brain and colon samples. (A)} Box plots showing differences between average Beta values of $5 \mathrm{mC}+5 \mathrm{hmC}(\mathrm{BS})$ and true $5 \mathrm{mC}(\mathrm{OxBS})$ in both normal brain and colon. On the right are Hilbert curves showing the amount and genomic distribution of $5 \mathrm{hmC}$ in brain and colon. (B) Associations between $5 \mathrm{hmC}$ and $\mathrm{CpG}$ density. (C) Distribution of 5hmC $\mathrm{CpG}$ sites relative to $\mathrm{CpG}$ island status and compared to the array background (450K). (D) Distribution of $5 \mathrm{hmC} \mathrm{CpG}$ sites relative to different genomic regions. (E) Heatmaps showing significant enrichment of the $5 \mathrm{hmC} \mathrm{CpG} \mathrm{sites,} \mathrm{identified} \mathrm{in} \mathrm{brain} \mathrm{and} \mathrm{colon,}$ with different histone marks contained in the UCSC Browser Broad Histone track from the ENCODE project. Color code indicates the significant enrichment based on log2 odds ratio (OR).

Figure 3. Alterations of $5 \mathrm{hmC}$ in CRC and glioma. (A) Bar plot showing the number of dh5mC sites in CRC and glioma. (B) Unsupervised hierarchical clustering and heatmap including $\mathrm{CpG}$ sites with $5 \mathrm{hmC}$ loss in glioma. (C) Associations between $5 \mathrm{hmC}$ loss in glioma and density of CpGs (upper panel), $\mathrm{CpG}$ island status (middle panel), and different genomic regions (lower panel). (D) Heatmaps showing significant enrichment of hypo $5 \mathrm{hmC} \mathrm{CpGs}$ identified in glioma with different histone marks contained in the UCSC Browser Broad Histone track from the ENCODE project. (E) Heatmaps showing significant enrichment of hypo $5 \mathrm{hmC} \mathrm{CpGs} \mathrm{in} \mathrm{gliomas} \mathrm{with} \mathrm{fifteen}$ "chromatin states" generated by a Hidden Markov Model (HMM) (right panel). Color codes indicate the significant enrichment based on $\log 2$ odds ratio (OR).

Figure 4. Relationships between changes in $5 \mathrm{mc}$ and $5 \mathrm{hmc}$ in glioma. (A) Euler diagram illustrating overlap of CpGs that lose $5 \mathrm{hmC}$ (hypo 5hmC) and gain $5 \mathrm{mC}$ (hyper $5 \mathrm{mC}$ ) in glioma. (B) Associations between hypermethylated $\mathrm{CpG}$ sites that lose (or not) 5hmC and $\mathrm{CpG}$ density and $\mathrm{CpG}$ island status, compared to the array background 
840 (450K). (C) Unsupervised hierarchical clustering and heatmap including CpG sites with

$8415 \mathrm{mC}$ changes (hyper- and hypomethylation) in glioma. Hypo- (purple) and non-hypo

842 (orange) $5 \mathrm{hmC}$ overlapped $\mathrm{CpGs}$ are indicated by colored lines on the annexed track.

843 Average beta methylation values are displayed from 0 (blue) to 1 (yellow).

845 Figure 5. Canonical and non-canonical hypermethylation in glioma. (A) Heatmaps

846 showing significant enrichment of $\mathrm{CpG}$ sites in glioma which exclusively gain $5 \mathrm{mC}$

847 (canonical hypermethylation) (upper panel), and both lose $5 \mathrm{hmC}$ and gain $5 \mathrm{mC}$ (non-

848 canonical hypermethylation) (lower panel), with different histone marks contained in

849 the UCSC Browser Broad Histone track from the ENCODE project. Histone PTMs

850 related to activation and repression are distinguished by colors as indicated in the key.

851 (B) Circular representation of two representative chromosomes (12 and 17), indicating

852 genomic location of canonical (orange) and non-canonical (purple) hypermethylation in

853 glioma. Inner tracks display chromatin marks (H3K9me3, H3K27me3, and H3K4me2),

854 generated for NH-A cells. Two examples of genes showing canonical and non-canonical

855 hypermethylation associated with specific chromatin signatures are displayed below.

857 Figure 6. Functional role of canonical and non-canonical hypermethylation in

858 glioma. (A) Euler diagrams showing number of genes associated with canonical

859 hypermethylation, non-canonical hypermethylation, or both. On the right are

860 representative gene ontology terms (Biological process) of genes associated with

861 canonical (orange) and non-canonical (purple) hypermethylation, ranked by Q-value,

862 and enrichment score (relative risk). (B) Euler diagram showing overlap of canonical

863 and non-canonical hypermethylated genes with down-regulation. (C) Associations of

864 canonical and non-canonical hypermethylation in glioma with different genomic

865 regions. (D) Representative example of one gene (SLC1A4) showing non-canonical

866 hypermethylation in glioma (orange frame). Organization of the gene, locations of

867 CpGs included in the methylation array (black dots), and transcription start site (TSS)

868 are shown below. $5 \mathrm{mC}$ hypermethylation (blue to yellow) and $5 \mathrm{hmC}$ loss (gray to blue)

869 in glioma are shown above. Whole genome bisulfite sequencing (WGBS) data [42]

870 including all the $\mathrm{CpG}$ sites in the same region are shown on the right. The associated

871 change in gene expression is displayed below. 
bioRxiv preprint doi: https://doi.org/10.1101/193789; this version posted September 26, 2017. The copyright holder for this preprint (which was not certified by peer review) is the author/funder, who has granted bioRxiv a license to display the preprint in perpetuity. It is made available under aCC-BY 4.0 International license.

\section{Supplementary Tables 1-12}

875 Supplementary figures 1-4 
bioRxiv preprint doi: https://doi.org/10.1101/193789; this version posted September 26, 2017. The copyright holder for this preprint (whipigure 1 was not certified by peer review) is the author/funder, who has granted bioRxiv a license to disp
available under aCC-BY 4.0 International license.

a.

Total samples

N: $12 \quad T: 51 \quad$ Glioma $5 \mathrm{mC}$

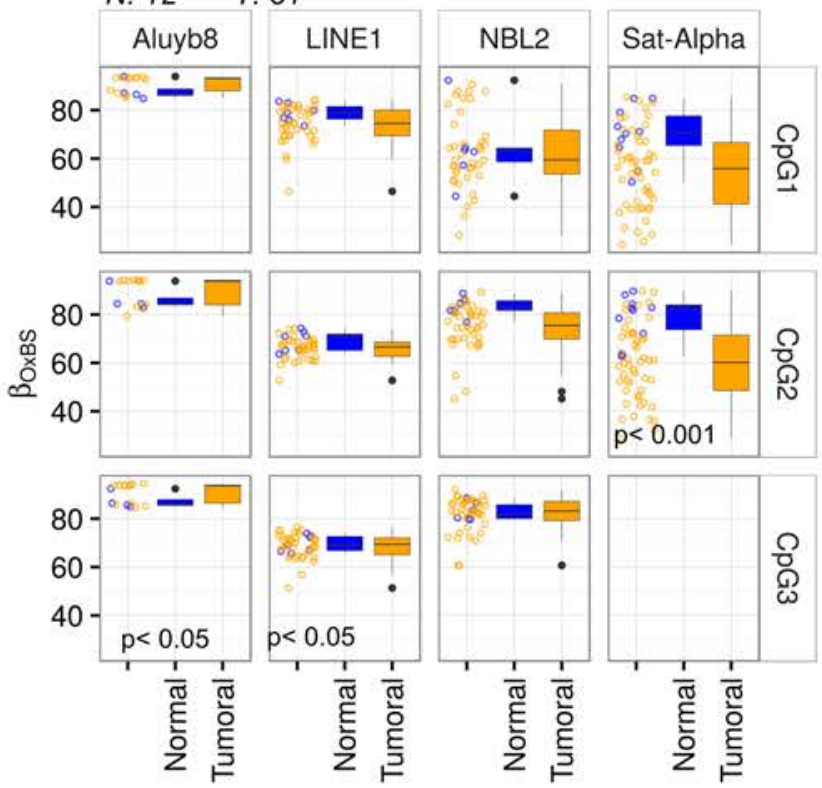

b.

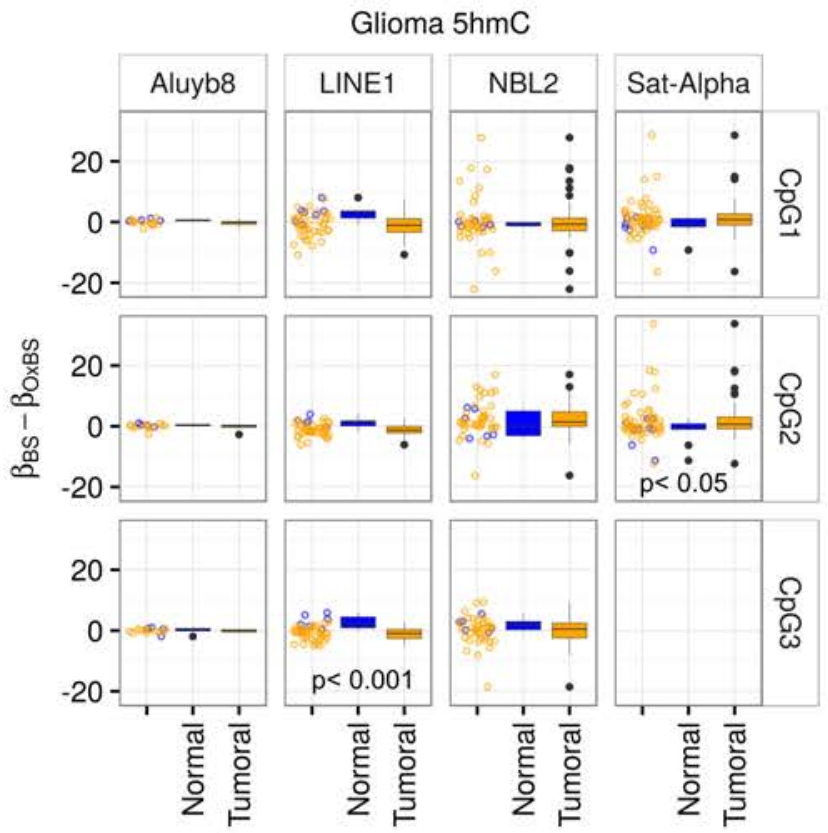

Total samples

N: $72 \quad T: 72$ Colon $5 \mathrm{mC}$

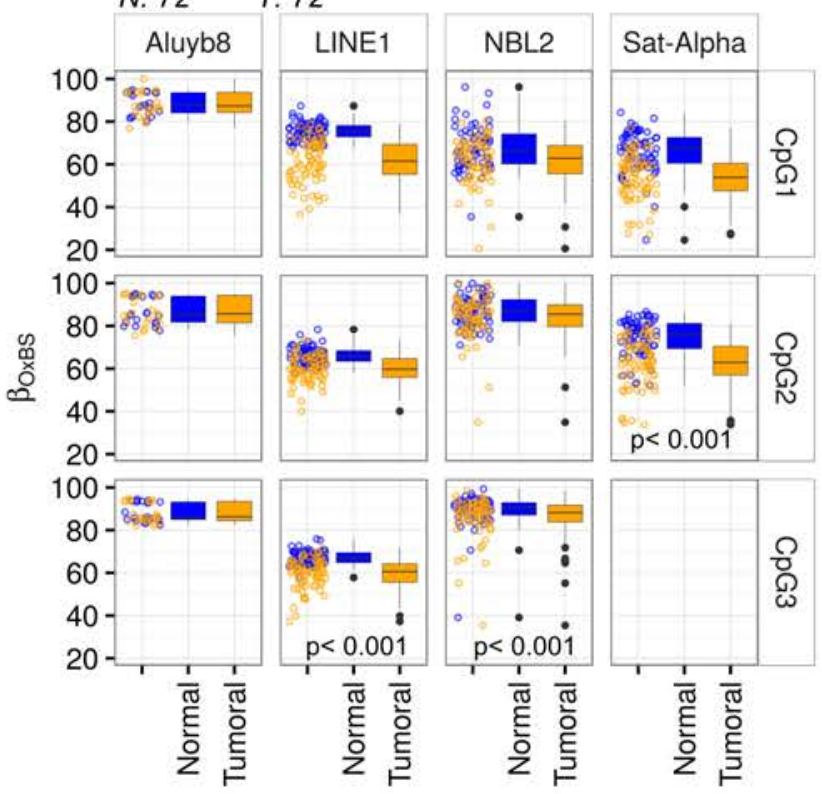

Colon $5 \mathrm{hmC}$

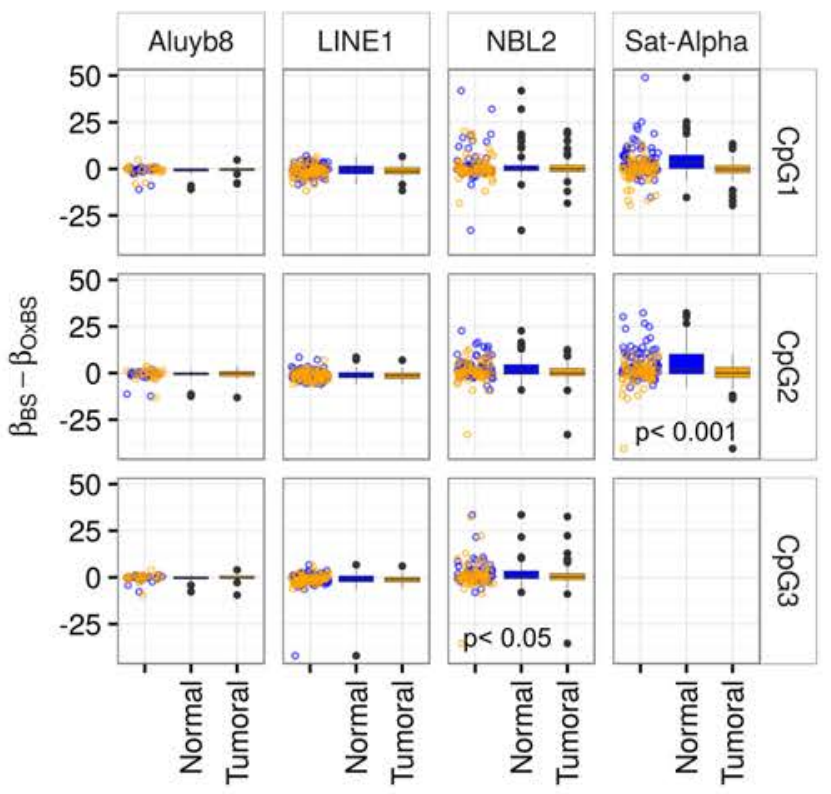


a.

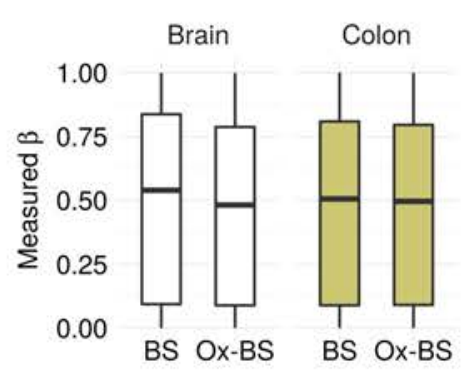

Brain

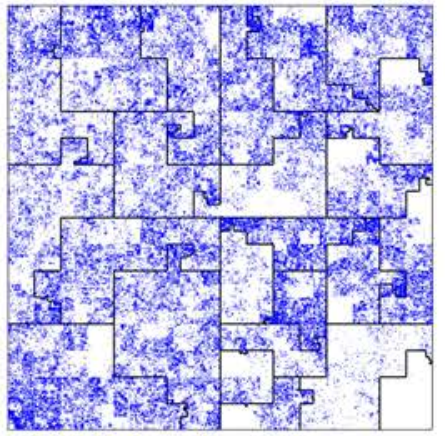

CpG sites: 111633
Colon

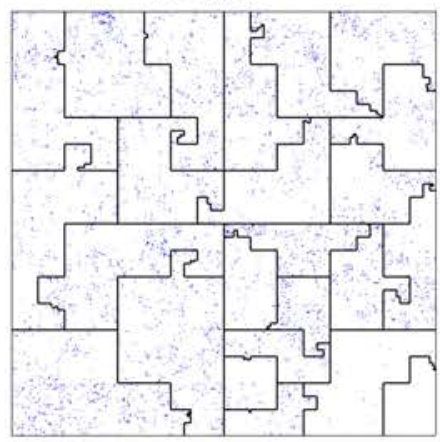

CpG sites: 5089 b.

$5 \mathrm{hmc}$

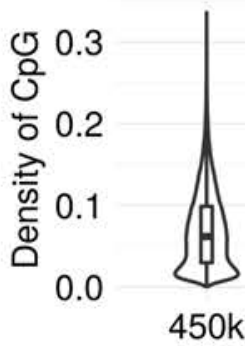

e.

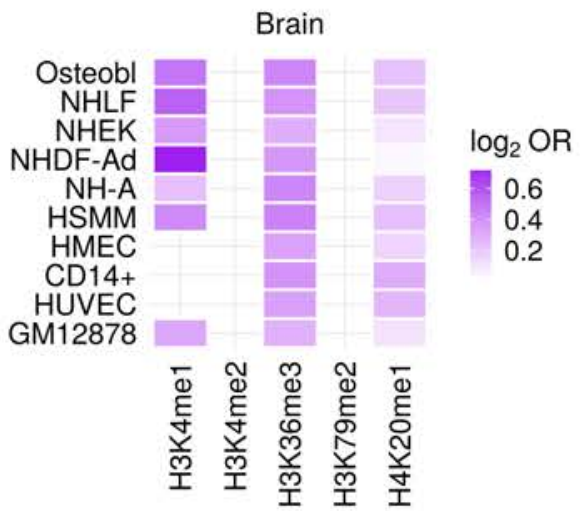

c.

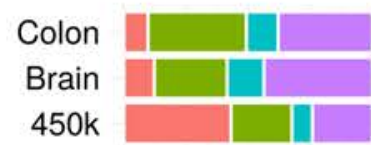

d.
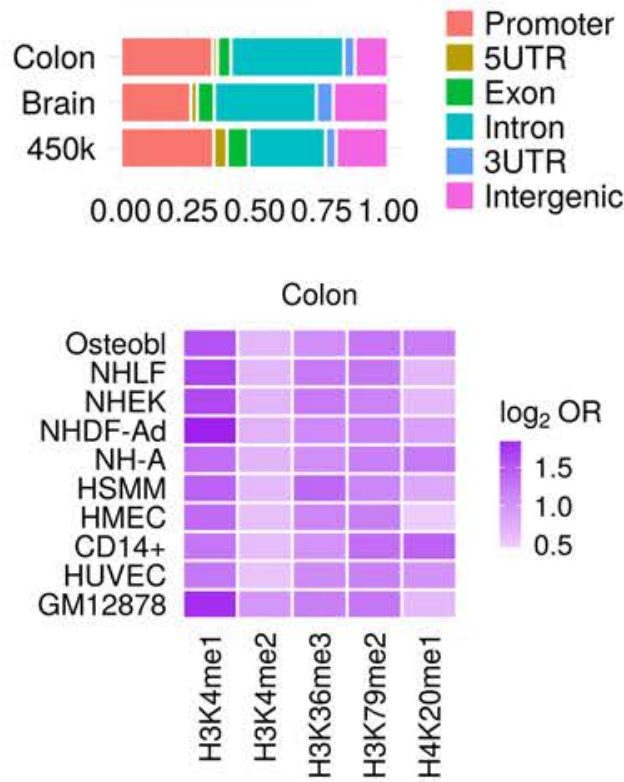
a.

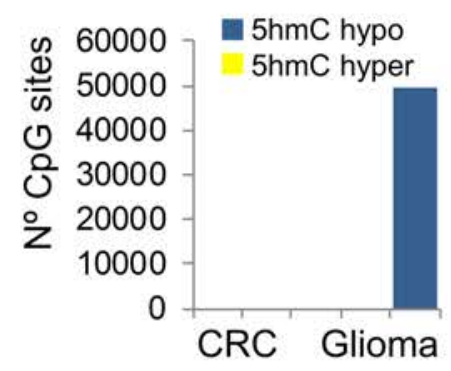

c.

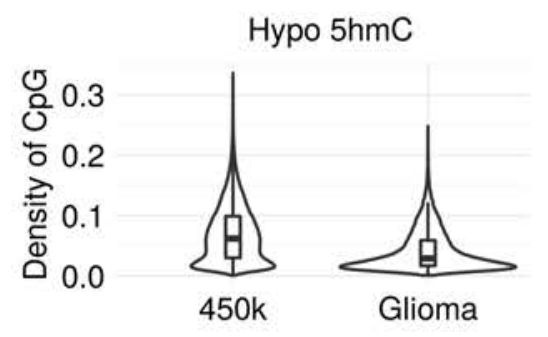

Glioma Hypo 5hmC

$450 \mathrm{k}$
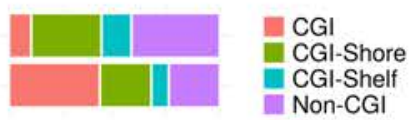

Glioma Hypo 5hmC

$450 \mathrm{k}$

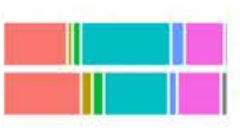

ㅍ.1. Promoter

5UTR

Exon

- Intron

$\begin{array}{lllll}0.00 & 0.25 & 0.50 & 0.75 & 1.00\end{array}$

3UTR

d.

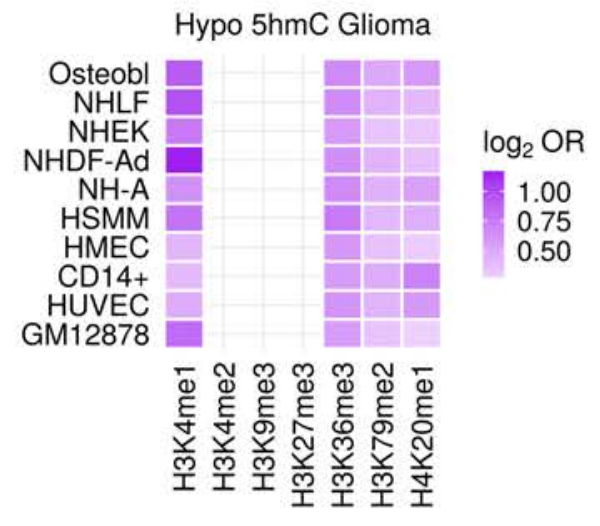

b.

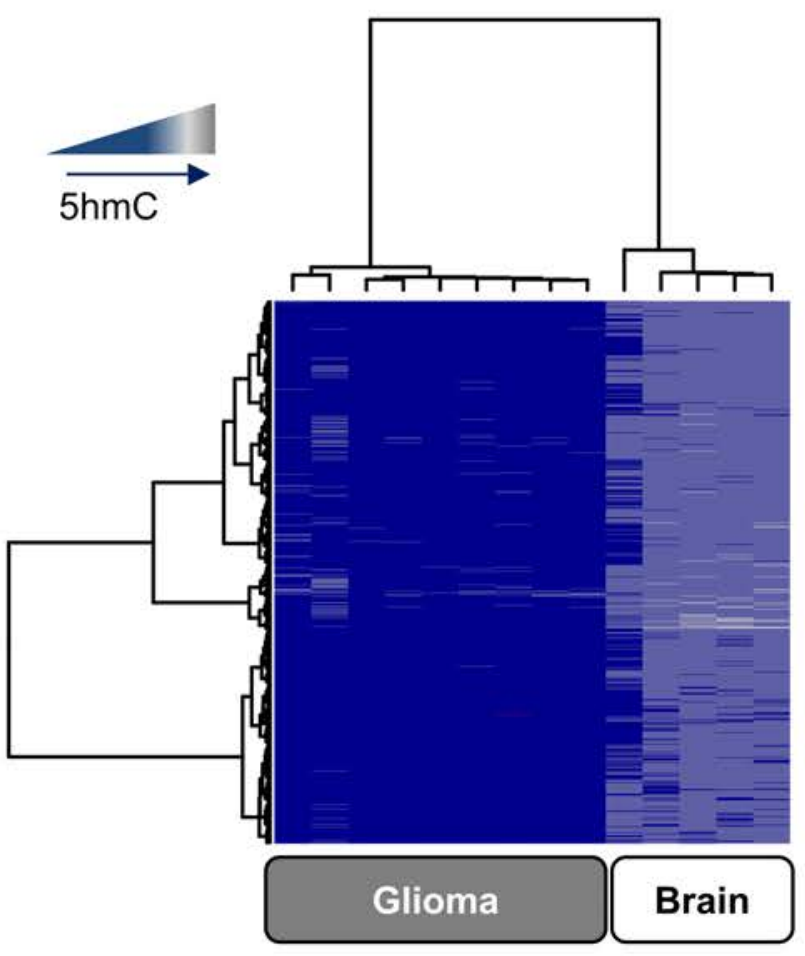

e.

\section{Hypo 5hmC Glioma}

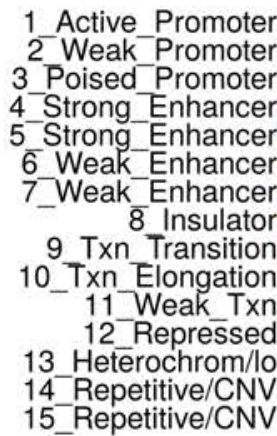
Log2OR

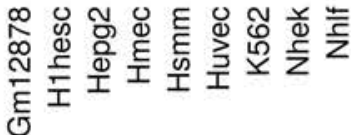


bioRxiv preprint doi: https://doi.org/10.1101/193789; this version posted September 26, 2017. The copyright holder for this preprint (whiфhigure 4 was not certified by peer review) is the author/funder, who has granted bioRxiv a license to display the preprint in perpetuity. It is made available under aCC-BY 4.0 International license.

a.

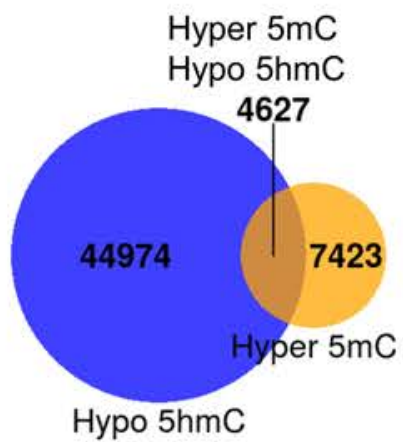

b.

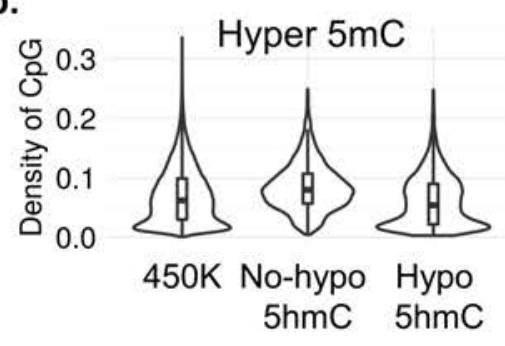

Hyper $5 \mathrm{mC}$

Hypo $5 \mathrm{hmC}$ No-hypo $5 \mathrm{hmC}$

$450 \mathrm{~K}$

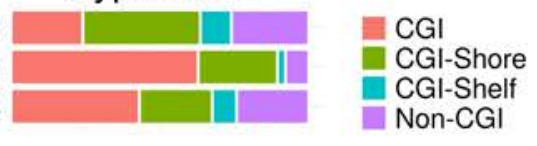

$\begin{array}{lllll}0.00 & 0.25 & 0.50 & 0.75 & 1.00\end{array}$

c.

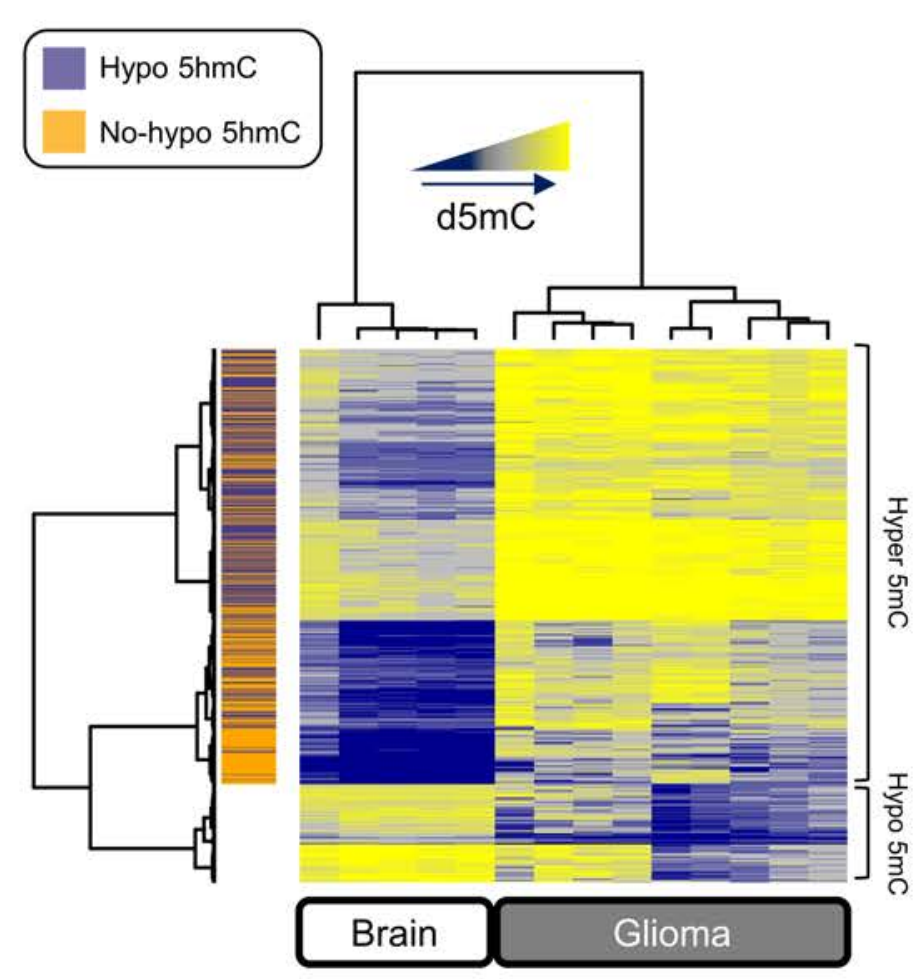


a.

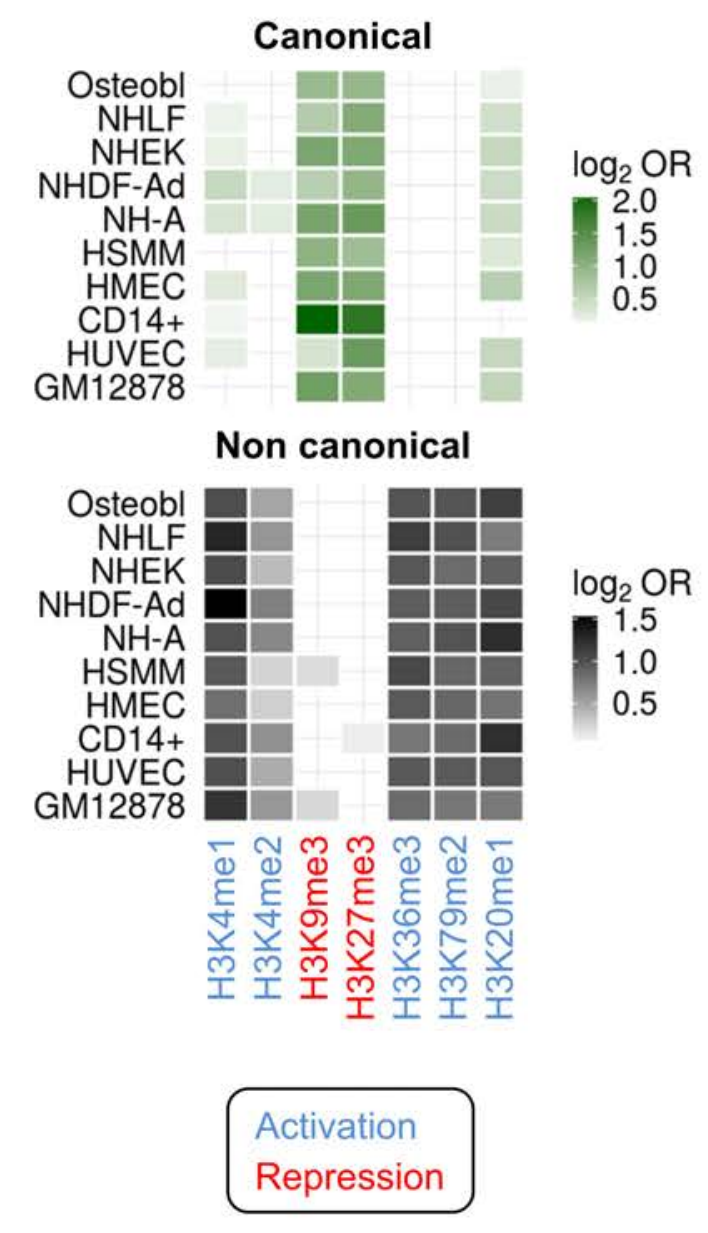

b.

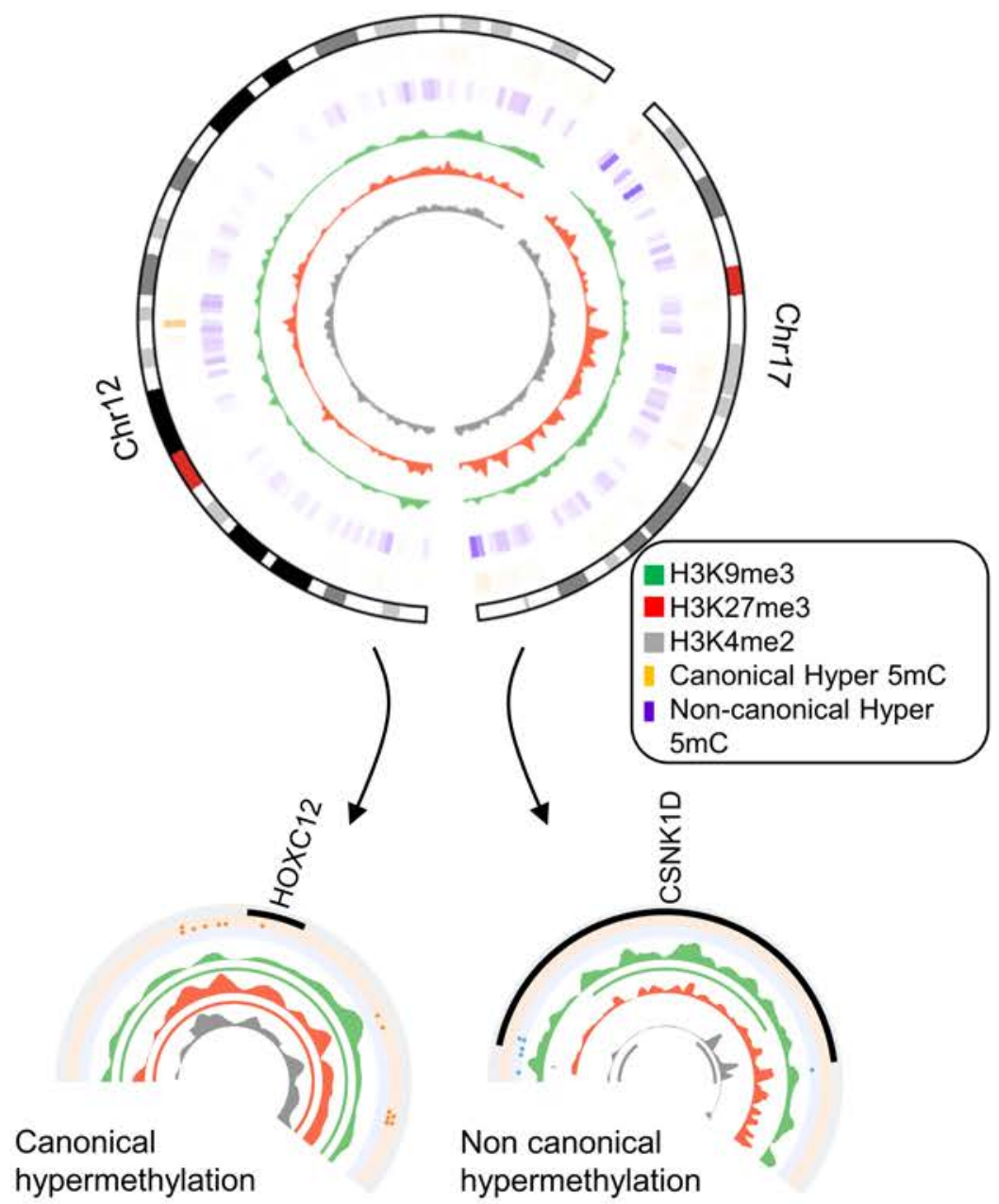


bioRxiv preprint doi: https://doi.org/10.1101/193789; this version posted September 26, 2017. The copyright holder for this preprint (whip $\mathbf{F}$ igure $\mathbf{6}$ was not certified by peer review) is the author/funder, who has granted bioRxiv a license to display the preprint in perpetuity. It is made available under aCC-BY 4.0 International license.

a.

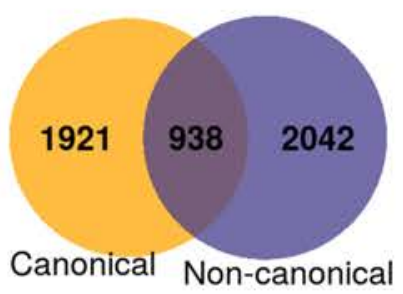

b.

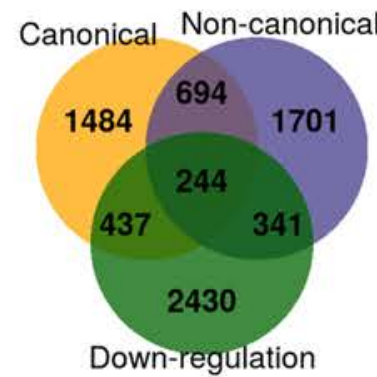

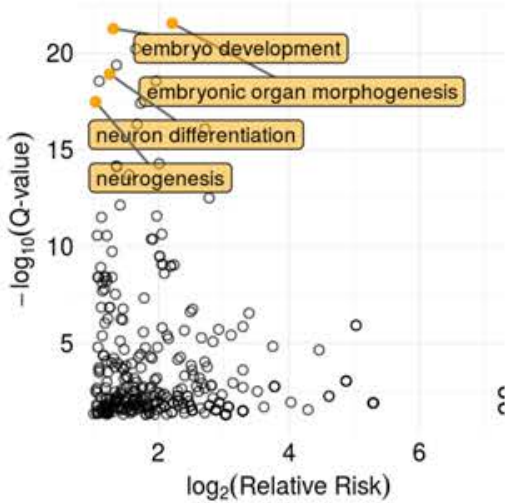

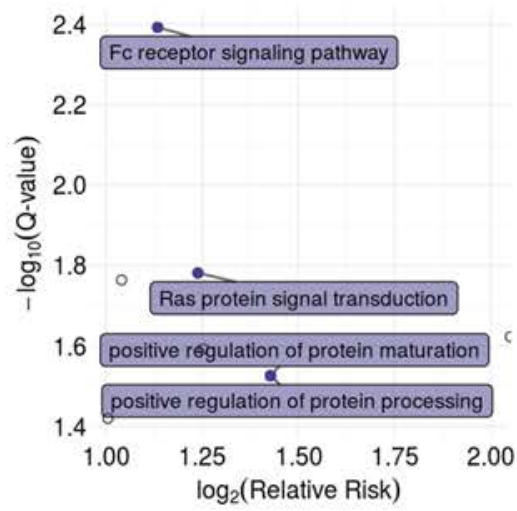

c.

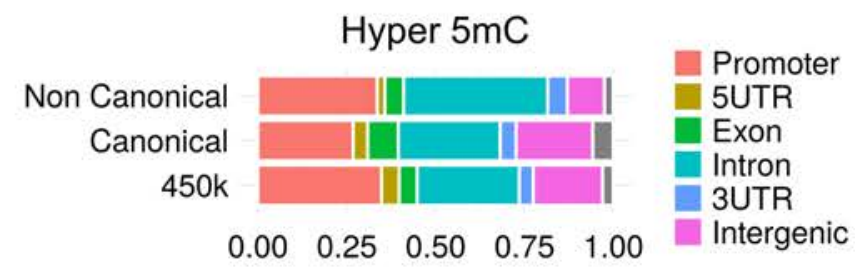

d.

Chromosome 2 पाला|णमाणाएणाए

\begin{tabular}{|c|c|}
\hline $65.22 \mathrm{mb}$ & $65.24 \mathrm{mb}$ \\
\hline
\end{tabular}
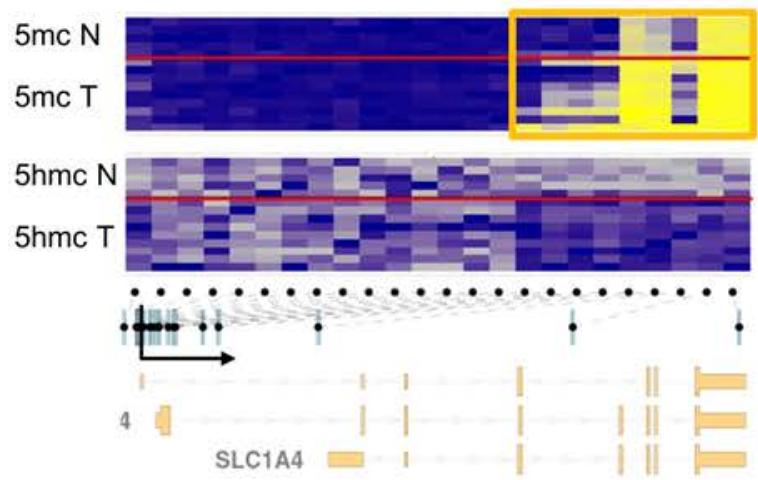
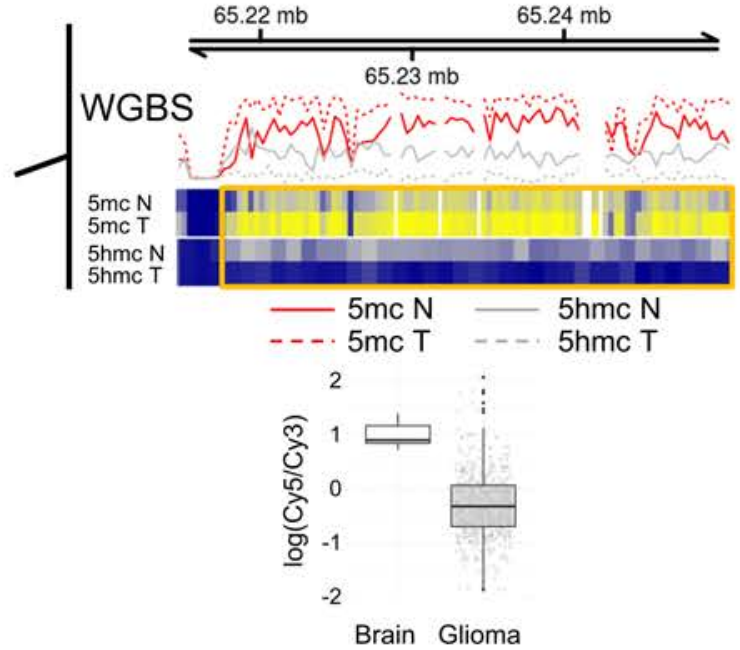
Figure 4-figure supplement 1

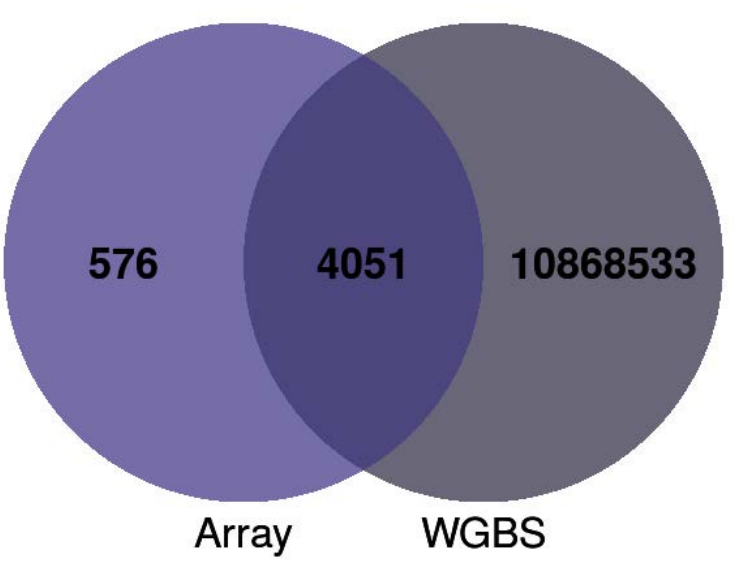

Figure 4-figure supplement 1. Venn diagram showing the overlap of hyper5mC-hypo5hmC sites in glioma obtained by methylation arrays and whole genome bisulfite sequencing (WGBS). 

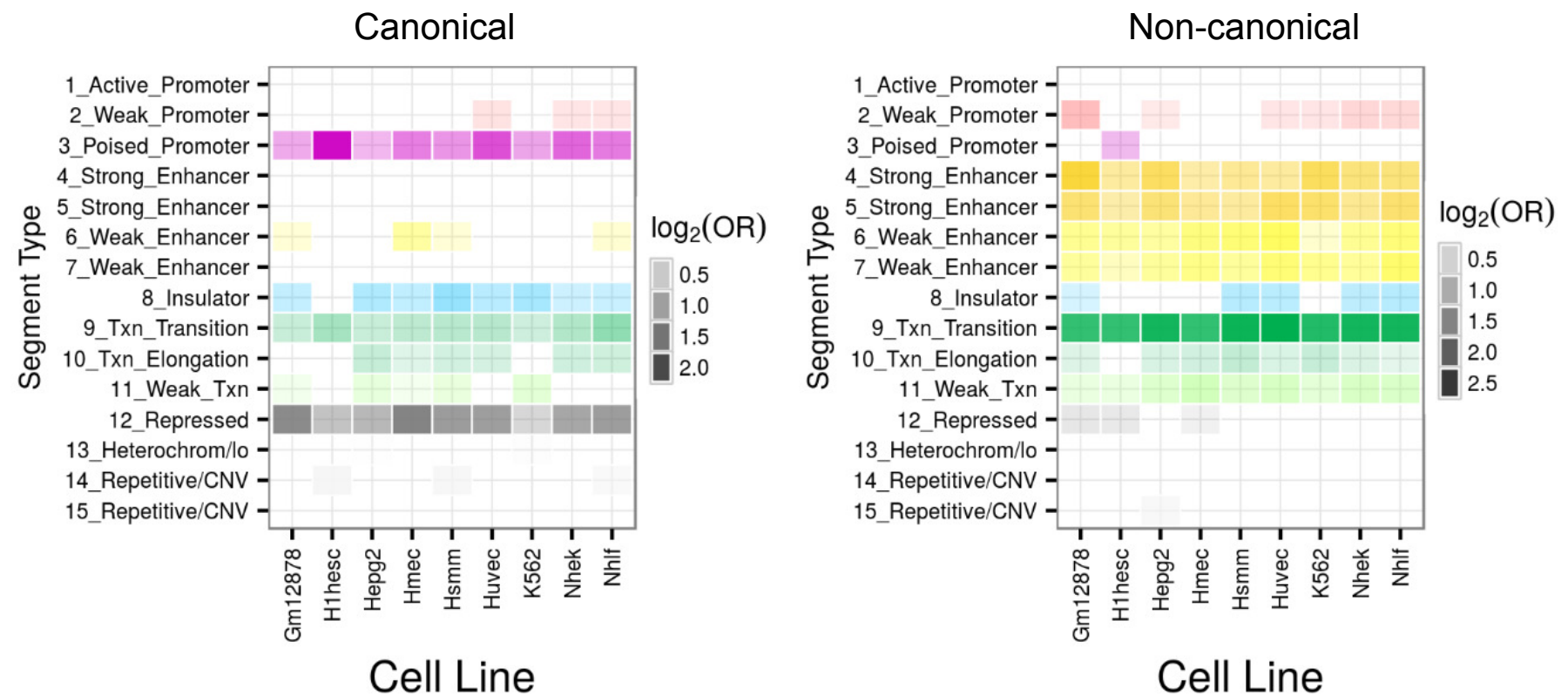

Figure 5-figure supplement 1. Canonical and non-canonical hypermethylation in glioma. Heatmaps showing significant enrichment of canonical (left panel) and non-canonical (right panel) hypermethylated CpG sites with fifteen "chromatin states" generated by a Hidden Markov Model (HMM). Colour codes indicate the significant enrichment based on $\log _{2}$ odds ratio (OR). 


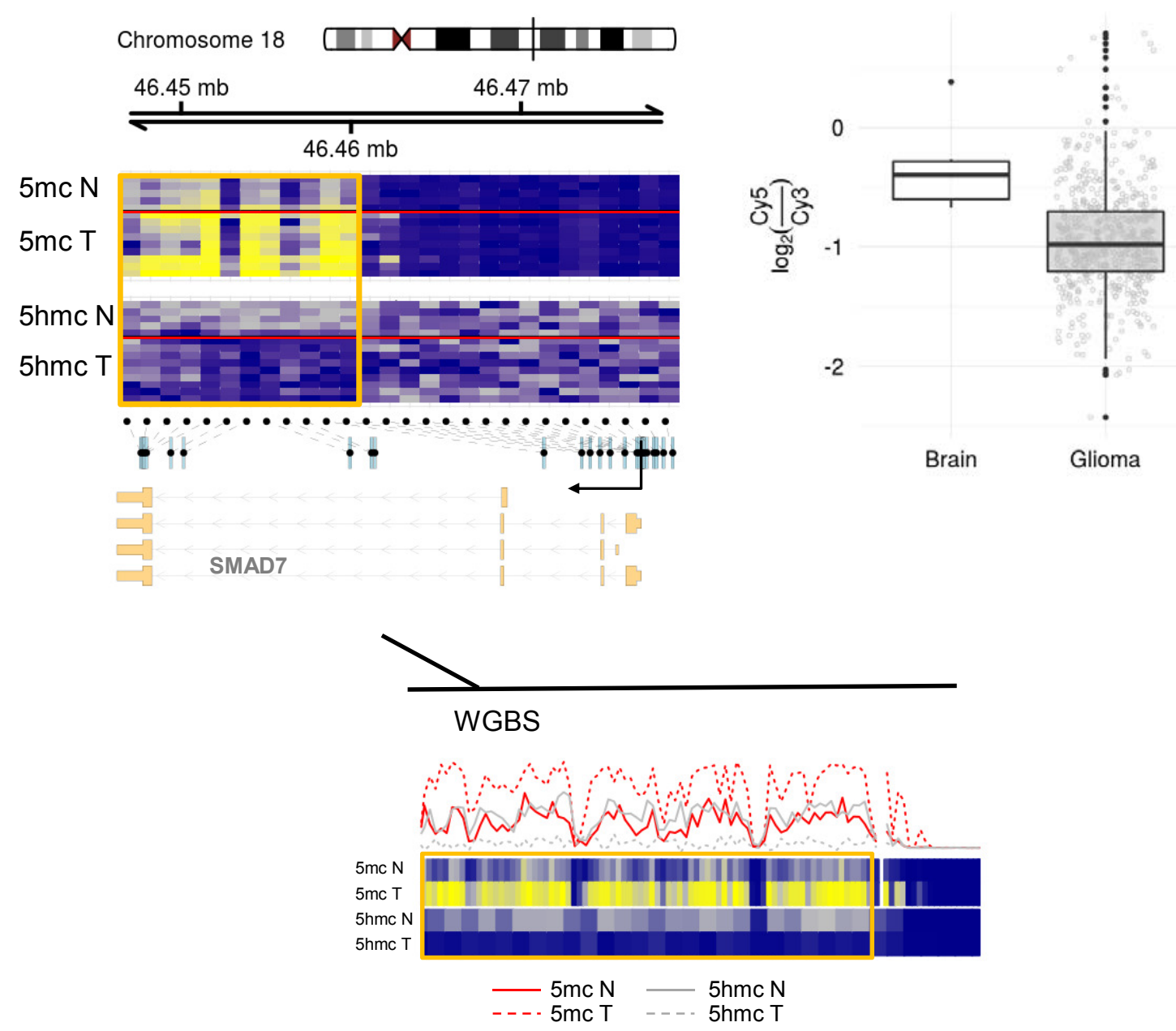

Figure 6-figure supplement 1. Functional role of non-canonical hypermethylation in glioma. Representative example of one gene (SMAD7) showing non-canonical hypermethylation in glioma (orange frame). Organization of the gene, location of CpGs included in the methylation array (black dots), and transcription start site (TSS) are shown below. $5 \mathrm{mC}$ hypermethylation (blue to yellow) and $5 \mathrm{hmC}$ loss (gray to blue) in gliomas are shown above. Lower panel shows the full genome bisulfite sequencing (WGBS) data including all the CpG sites in the same region. The associated change in gene expression is shown on the right. 
a.
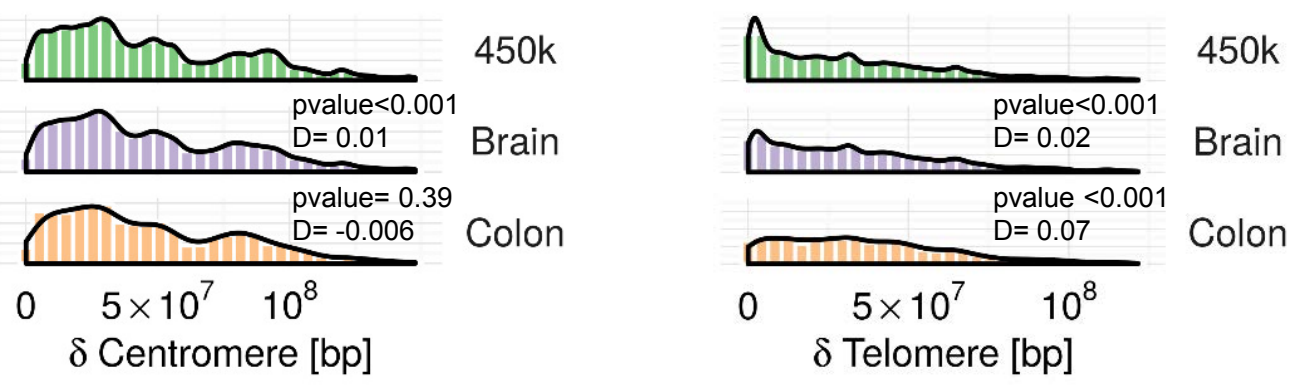

b.
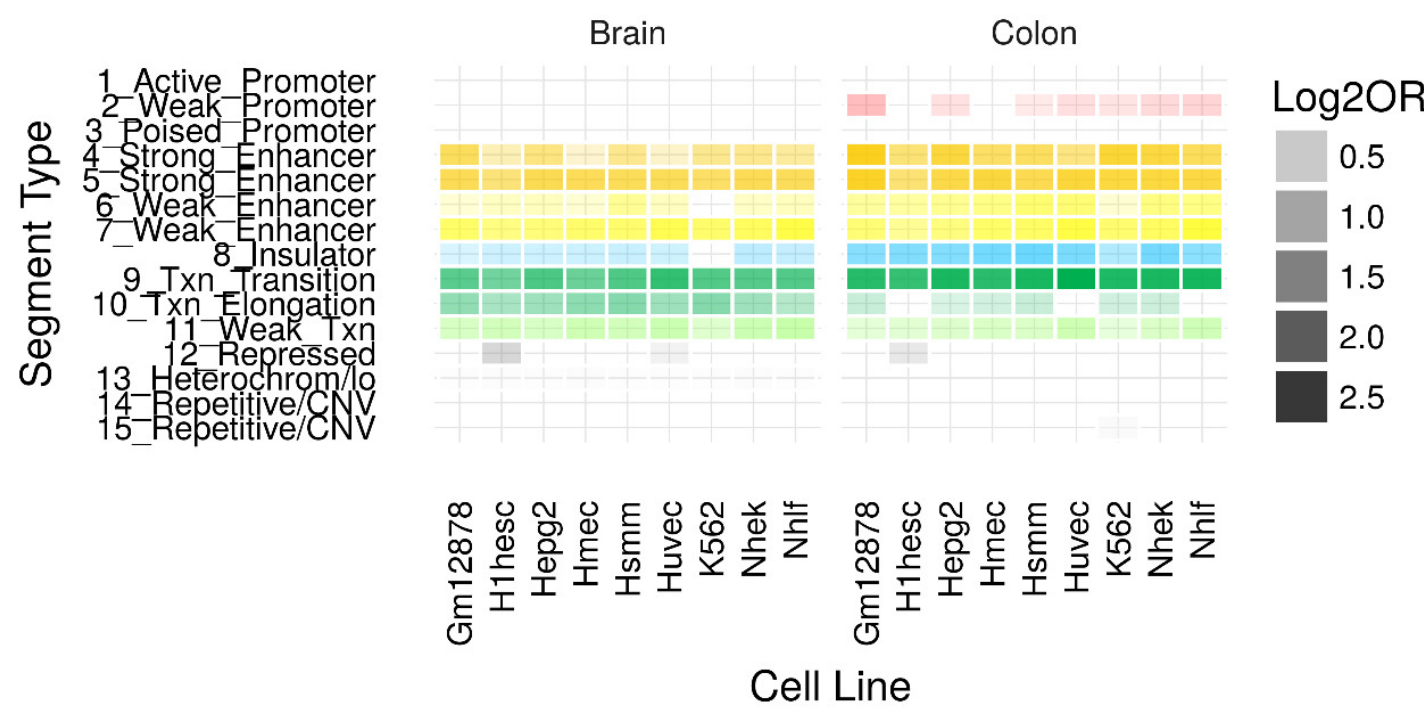

Figure 2-figure supplement 1. Characterization of DNA $5 \mathrm{hmC}$ in normal brain and colon samples. (a) Histograms and density plots showing the associations between $5 \mathrm{hmC} \mathrm{CpGs}$ and distance to centromere (left) and telomeres (right). (b) Heatmaps showing significant enrichment of 5hmC CpG sites with fifteen "chromatin states" generated by a Hidden Markov Model (HMM). Colour codes indicate the significant enrichment based on $\log _{2}$ odds ratio (OR). 